\title{
Gull Eggs as Indicators of Mercury Bioavailability: Application of Amino Acid-Compound Specific Nitrogen Isotope Analysis
}

\author{
by
}

Svetlana Dolgova

A thesis submitted to the Faculty of Graduate and Postdoctoral Affairs in partial fulfillment of the requirements for the degree of

Master of Science

in

Biology

Carleton University

Ottawa, Ontario

(C) 2017, Svetlana Dolgova 


\begin{abstract}
Spatial trends in levels of biomagnifying environmental contaminants in tissues of top predators can provide insights into potential contaminant sources and dynamics, as well as inform efforts to control contaminant releases into the environment. Here, I use gull eggs to elucidate spatial trends in environmental availability of mercury in western Canada. I begin by validating the use of eggs as a matrix for monitoring mercury bioavailability through an experimental laboratory study. Next, I investigate mercury spatial trends in wild gull eggs collected at twelve sites located across 14 degrees of latitude. Assessing levels of biomagnifying contaminants can be confounded by dietary variability, therefore I apply amino acid-compound specific stable nitrogen isotope analysis (AA-CSIA) to generate trophic-position adjusted mercury levels that are more suitable for spatial comparisons. Spatial differences in egg mercury levels were evident with highest values observed at sites in receiving waters of the Athabasca River. My research demonstrates the utility of the AA-CSIA approach in enhancing our ability to interpret contaminant monitoring data collected through biomonitoring programs.
\end{abstract}




\section{Acknowledgments}

\section{"Яйца курииу не учат." \\ - Russian Proverb ( "Eggs don't teach a hen," roughly)}

I would like to thank the Athabasca Chipewyan First Nation, the Mikisew Cree First Nation, and Métis Local 125 for supporting this research and for granting permission to collect samples on their traditional territories. A. McGregor and G. Chapman (Alberta Environment and Sustainable Resource Development); D. Campbell, Q. Gray, J. Lankshear, L. Patterson, J. Straka, (Parks Canada Agency); J. Obst, L. Parker (CanNorth Environmental Services); R. Espie and S. Wilkie (Saskatchewan Environment); and E. Seed assisted with egg collections. The staff at the Tissue Processing Laboratory, National Wildlife Research Centre, is thanked for their expert advice. Emily Porter, Doug Crump, and Kim Williams, for help and advice with egg injection work. N. Wallsgrove and C. Ka'apu-Lyons conducted the AA-CSIA. Environment and Climate Change Canada's N. Burgess, L. Champoux, S. DeSolla, D. Duncan, J. Elliott, P. Martin, and C. Weseloh contributed egg samples for the analysis depicted in Figure 3.1.

Carleton University and Biology graduate administrators are thanked for ongoing support. Committee members Dr. Joseph Bennett, Dr. Jules Blais, Dr. Andrew Simons are thanked for their time and efforts. Spasibo to Dr. Craig Hebert at ECCC for occasional snacks.

This research was funded by Environment and Climate Change Canada and by the Joint Canada-Alberta Oil Sands Monitoring Program. Additional support came from Fonds de recherche du Québec - Nature et technologies (FRQNT). 


\section{Table of Contents}

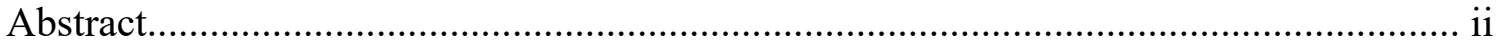

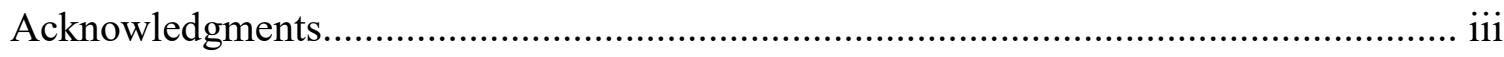

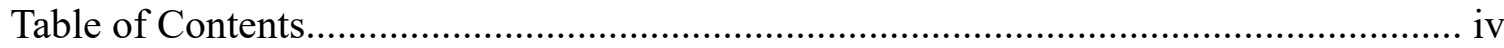

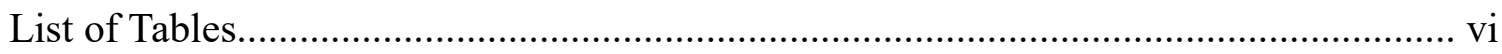

List of Figures................................................................................................ vii

CHAPTER ONE GENERAL INTRODUCTION $\quad$ G................................................ 1

CHAPTER TWO UTILITY OF EGGS AS BIOINDICATORS AND INFLUENCE OF STAGE OF DEVELOPMENT ON EGG MERCURY CONCENTRATIONS ...................................................... 16

Introduction.................................................................. 17

Methods......................................................................... 24

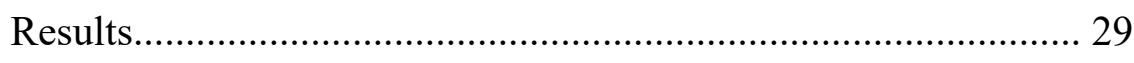

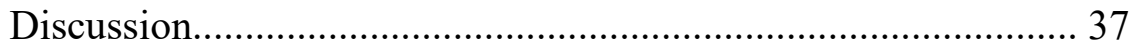

CHAPTER THREE APPLICATION OF AMINO ACID-COMPOUND SPECIFIC NITROGEN ISOTOPE ANALYSIS FOR ASSESSING SPATIAL TRENDS IN MERCURY.................................................. 41

Introduction............................................................... 42

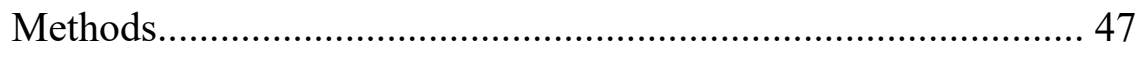

Results...................................................................... 53 


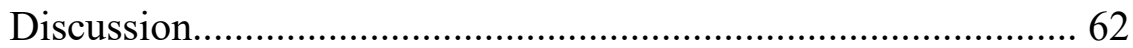

CHAPTER FOUR GENERAL SUMMARY..................................................... 69

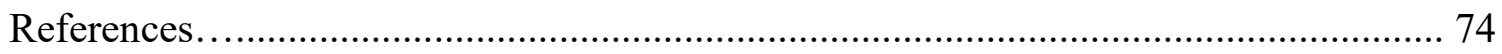




\section{List of Tables}

Table 1.1 Summary of collection sites with number of eggs collected. Stage of incubation is the average stage of development of eggs collected at each site; it is expressed as a proportion of the period necessary for completion of incubation. Incubation periods are species-specific: Herring Gull $(\mathrm{HERG})=28$ days, Ring-Billed Gull $(\mathrm{RBGU})=27$ days, California Gull $(\mathrm{CAGU})=26$ days (Birds of North America, online) 14

Table 2.1 $\delta^{34} \mathrm{~S}$ values in egg pools of Herring Gulls (HERG), California Gulls (CAGU) and Ring-Billed Gulls (RBGU) collected in 2014. Site numbers correspond to

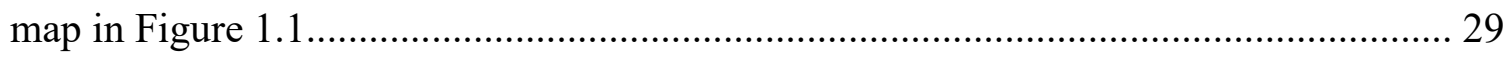

Table 3.1 Water chemistry parameters for sites in western Canada........................ 61 


\section{List of Figures}

Figure 1.1 Gull eggs were collected in 2014 and 2015 from the 12 numbered locations spanning a 14 degree latitudinal gradient. Samples from these sites were used to examine spatial patterns in egg mercury levels

Figure 1.2 Colonial waterbird study species. RBGU - Ring-Billed Gull (Larus delawarensis); CAGU - California Gull (Larus californicus); HERG - Herring Gull (Larus

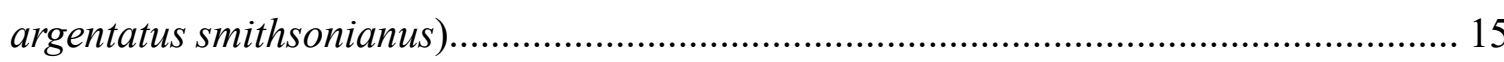

Figure 2.1 Mean ( \pm 1 STD) dry weight mercury concentration in chicken eggs dosed with $\mathrm{MeHg}$ at day 0. Eggs were sampled throughout incubation. Stage of incubation is expressed as a proportion of the 21-day incubation period. Sample sizes are indicated above each point. Egg Hg concentrations were statistically greater in late stage incubated eggs ( $86 \%$ of total incubation period) compared to eggs at $43 \%$ incubation

Figure 2.2 Mean ( \pm 1 STD) dry weight mercury concentration in chicken eggs dosed with $\mathrm{MeHg}$ at day 0. Eggs were sampled at the beginning and end of incubation. Eggs at late stage of total incubation period had significantly higher concentrations of mercury than eggs sampled at early stage of total incubation period, representing a $14.5 \%$ increase. Sample sizes are indicated above the means. 33

Figure 2.3 Relationship between the proportion of the incubation period completed when gull eggs were collected and the incubation adjustment factor... 35 
Figure 2.4 Mean adjusted ( \pm 1 STD) dry weight mercury concentration in chicken eggs dosed with $\mathrm{MeHg}$ at day 0. Eggs were sampled at the beginning and end of incubation. Levels of mercury adjusted for stage of development were not statistically different between eggs at early or late stages of incubation. Sample sizes are indicated above the

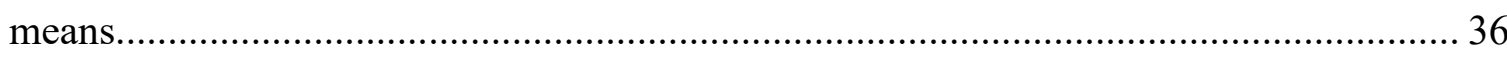

Figure 3.1 Statistically significant relationship between $\delta^{15} \mathrm{~N}_{\text {BulkPhe }}$ and $\delta^{15} \mathrm{~N}_{\text {GluPhe }}$ values in gull egg pools from 25 locations across Canada....... 53

Figure 3.2 Concentrations of mercury $\left(\mu \mathrm{g} \cdot \mathrm{g}^{-1}\right.$, dry weight) in individual gull eggs increase with latitude $\left(r_{s}=0.50, p<0.001\right)$. Mercury levels are adjusted for stage of embryonic development (see text). See Figure 1.1 for corresponding site names 55

Figure 3.3 Latitude is weakly correlated with bulk $\delta^{15} \mathrm{~N}$ values (\%o) in individual gull

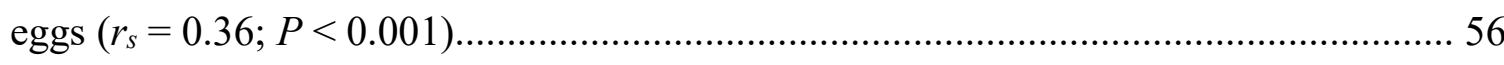

Figure 3.4 Latitude is strongly correlated with egg $\delta^{15} \mathrm{~N}$ values (\%o) normalized for isotopic baselines (egg $\left.\delta^{15} \mathrm{~N}_{\text {bulk }}-\delta^{15} \mathrm{~N}_{\text {Phe }}\right)\left(r_{s}=0.68, P<0.001\right)$ 57

Figure 3.5 Linear regression of egg $\delta^{15} \mathrm{~N}$ values (\%) normalized for isotopic baselines versus egg THg levels $\left(r^{2}=0.24, P<0.001\right)$. Mercury levels are adjusted for stage of embryonic development (see text). Residuals (examples in red) from the regression are egg $\mathrm{THg}$ levels normalized for trophic position.................................................... 58 
Figure 3.6 Egg THg levels normalized for trophic position and stage of development are weakly correlated with latitude $\left(r_{s}=0.18, P<0.001\right)$. However, distance-weighted least squares curve fitting (black line) indicated that other spatial differences in egg THg levels also exist, i.e. levels at sites 6-8 appear elevated 59

Figure 3.7 Comparison of regional mean ( $\pm 95 \%$ confidence intervals) egg THg levels normalized for stage of development and trophic position. Sites were categorized into one of three regions: south $\left(<58^{\circ} \mathrm{N}\right.$, sites $\left.1-5\right)$, downstream (DS) of the Athabasca River $\left(58.9^{\circ} \mathrm{N}-59.2^{\circ} \mathrm{N}\right.$, sites $\left.6-8\right)$ or north $\left(>59.2^{\circ} \mathrm{N}\right.$, sites $\left.9-12\right)$. Mean normalized egg THg levels were greatest in eggs from DS sites (means with different letters are statistically different, Kruskal-Wallis test, post-hoc comparison of mean ranks, $P<0.05)$. Site numbers are

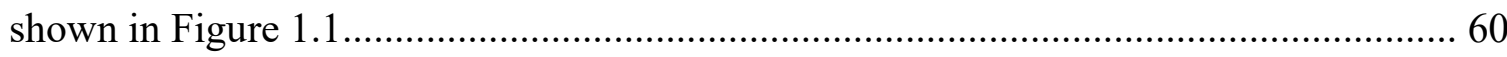


CHAPTER ONE

GENERAL INTRODUCTION 


\section{General Introduction}

\section{Mercury: Pathways and Toxicology}

Environmental contaminants, which can be released as a result of human activities, may cause adverse effects in organisms in terrestrial and aquatic ecosystems (Clarkson 1992; Wolfe et al. 1998). Understanding transport, fate, and exposure to such chemicals in organisms are fundamental goals of ecotoxicological studies. Mercury $(\mathrm{Hg})$, a bioaccumulating and biomagnifying contaminant, is of particular concern because it is a potent neurotoxin (Clarkson 1992) and concentrations in fish and wildlife have reached levels high enough to invoke human consumption advisories in parts of Canada (Alberta Health, 2007; Guide to Eating Ontario Sport Fish, 2016).

Mercury is a naturally occurring heavy metal. It is released into the environment through natural processes, mainly volcanic eruptions, forest fires and erosion, or as a byproduct from anthropogenic activities including burning of fossil fuels, waste incineration, and cement and steel production (Selin 2009). Once released into the atmosphere in its elemental gaseous form $(\operatorname{Hg}(0))$, it gets circulated globally by movement of air masses. Asia contributes roughly $50 \%$ of global atmospheric emissions of $\mathrm{Hg}$ and Asian demand for coal-based electricity is still on the rise, particularly in China (Pacyna et al. 2016). The atmosphere is an important vector for movement in the global Hg cycle (Schroeder and Munthe 1998). Given the long residence time of $\mathrm{Hg}$ in the atmosphere and the global circulation of air masses, $\mathrm{Hg}$ deposition may occur thousands of kilometres away from sources (Jaffe and Strode 2008). Within the Canadian Arctic, for example, foreign anthropogenic emissions contribute significantly to $\mathrm{Hg}$ deposition on a regional scale (NCP 2012). Deposition occurs as elemental mercury is oxidized to $\mathrm{Hg}(\mathrm{II})$ by photochemical 
processes in the atmosphere and precipitates on to terrestrial and aquatic surfaces (Selin 2009). Once in aquatic sediments, organic-rich and anaerobic conditions allow sulfurreducing bacteria to mediate the transformation of inorganic $\mathrm{Hg}$ to methylmercury $(\mathrm{MeHg})$; enhanced bacterial activity and subsequent methylation rates have been observed under low $\mathrm{pH}$ and high levels of dissolved organic carbon (Ullrich et al. 2001). Newly formed organic $\mathrm{MeHg}$ bioaccumulates in tissues of organisms and biomagnifies with each subsequent level in food chains, reaching highest concentrations in top predators. Unlike its inorganic forms, MeHg is readily absorbed and retained in tissues, leading to well documented reproductive, behavioural, neurological and physiological impairments in wildlife and humans (Clarkson 1992; Wolfe et al. 1998).

The ecotoxicology of $\mathrm{MeHg}$ has been studied in a variety of taxa, though wildlife field studies using large samples are limited (Wolfe et al. 1998). Primary exposure to $\mathrm{MeHg}$ in wildlife and humans is through dietary intake, particularly fish. Once ingested, $\mathrm{MeHg}$ is readily absorbed in the digestive tract and moves into the bloodstream whereby it is transported throughout the body as a complex bound to sulfhydryl groups of proteins (Clarkson 1992). Organic MeHg readily crosses the placenta and the blood-brain barrier. In birds, the embryo appears to be the life stage most sensitive to MeHg toxicity with $\mathrm{MeHg}$ being readily transferred from laying females to their eggs (Evers et al. 2003; Ackerman et al. 2016). Maternally deposited $\mathrm{Hg}$ is predominantly found in the albumen of eggs (Heinz and Hoffmann 2004). MeHg may impair reproduction by effects on embryonic viability, eggshell thickness, clutch size and nest fidelity (Scheuhammer et al. 2007). MeHg concentrations in bird eggs associated with impaired hatchability and embryonic mortality were found to be $>1 \mu \mathrm{g} / \mathrm{g}$ wet weight or approximately $>4 \mu \mathrm{g} / \mathrm{g}$ dry weight (Scheuhammer 
et al. 2007). There is evidence to suggest that relative to other feeding guilds, piscivorous waterbirds have higher MeHg toxicity thresholds (Heinz et al. 2009a); decreased sensitivity to $\mathrm{Hg}$ could reflect an adaptation of fish-eating birds to ameliorate potential effects of $\mathrm{Hg}$ stemming from high dietary exposure.

\section{Geographic Area of Interest}

Mercury concentrations in the environment are measured using various sampling matrices including: air (gaseous or particulate $\mathrm{Hg}$ levels in the atmosphere), water (both organic and inorganic species) and tissues (total Hg or organic MeHg) (NCP 2012). Due to its bioaccumulative and biomagnifying nature, $\mathrm{Hg}$ levels are greatest in top trophic level predators. As such, levels of biomagnifying contaminants in tissues of organisms at higher trophic levels are several orders of magnitude higher than at lower trophic levels, or in water or sediments (Norstrom et al. 1978). Hg concentrations in water to primary producers, for example, can increase by a factor of $10^{6}$ (Driscoll et al. 2007). Eggs of colonial waterbirds are reliable indicators of environmental levels of $\mathrm{Hg}$ and have been successfully used in marine monitoring programs in Atlantic, Arctic and Pacific regions of Canada (Burgess et al. 2013; Braune et al. 2015; Elliott and Elliott 2016) as well as in the Laurentian Great Lakes (Weseloh et al. 2011). However, there are gaps in knowledge regarding spatial trends in $\mathrm{Hg}$ concentrations in waterbirds nesting in inland waters in other parts of Canada. Northern Alberta is a region of particular interest given the relatively recent development of the Athabasca Oil Sands. Centred along the Athabasca River, just north of Fort McMurray and upstream of the Peace-Athabasca Delta, these deposits contain the third largest proven reserves of crude oil in the world (Giesy et al. 2010). Commercial 
scale development began in 1967 and has greatly increased since the 1990s (Stringham 2012). Despite the recent lower oil price environment and devastating regional wildfires around Fort McMurray, oil production is expected to reach 3.7 million barrels per day by the year 2030 (NRCAN 2014; EIA 2015; CAPP 2016).

Particular concern centres on the extent of dispersal of industry-derived contaminants downstream and downwind of the oil sands to sensitive ecosystems, including the Peace-Athabasca Delta (PAD). With its unique and relatively undisturbed landscape, the PAD offers refuge to an abundance of mammal, fish and bird species. In addition to its resident wildlife, the region is one of the most important waterfowl staging and migratory areas in Canada, hosting the only breeding population of the endangered Whooping Crane, Grus americana (Kuyt 1993; Butterworth 2002). Its ecological significance as the largest boreal delta in the world earned it the designation of a Ramsar Wetland of International Significance (Ramsar Convention Secretariat 2006). It is also the central feature of Wood Buffalo National Park, a UNESCO World Heritage site, marking it as a Canadian ecosystem of international significance.

The future health and environmental sustainability of this unique ecosystem have been of increasing concern with regard to regional industrial development. Indigenous groups in particular have been calling for increased protection and management of the PAD which they fear has been affected by hydro-electric and oil sands developments (MCFN 2014). Contamination of water and wildlife is cited as a direct threat to their traditional way of life which is critical to supporting the cultural, spiritual and physical survival of First Nation and Métis peoples (UNESCO/IUCN 2017). 
Environmental levels of $\mathrm{Hg}$ in northern Alberta have been studied using various abiotic matrices. Studies using snowmelt showed a link between oil sands development and increased levels of $\mathrm{Hg}$ in the environment downwind of industrial facilities (Kelly et al. 2010; Kirk et al. 2014); other studies using sediment cores found no evidence of atmospheric transport of oil sands-derived contaminants (Wiklund et al. 2012). Information from biotic indicators remains limited for $\mathrm{Hg}$ trends (fish - Evans and Talbot 2012; birds - Hebert et al. 2011, 2013), though studies have been conducted looking at other industrial air contaminants in that region and their effects on wildlife (Cruz-Martinez et al. 2014).

The Peace-Athabasca Delta is a complex ecosystem formed from unique hydrology and sediment deposition of two major rivers. The Athabasca River is a significant source of water and sediment to the PAD (Timoney 2013) and, therefore, is likely very important in terms of regulating possible riverine transport of contaminants to the Delta. It was previously suggested that the Athabasca River may be serving as a potential source of environmental contaminants to downstream locations (Hebert et al. 2011). In the Peace River, present MeHg baseline concentrations in various matrices (water, sediment, invertebrates, fish) are among the lowest in Canada (Site C Environmental Impact Statement 2013). However, current land use, especially the presence of dams and reservoirs, and future development projects, as well as geology of the Peace River watershed, may influence inorganic and organic $\mathrm{Hg}$ loadings to the PAD and Lake Athabasca and warrants further monitoring using both abiotic and biotic samples.

Spatial patterns of biomagnifying contaminants may reflect proximity to sources but they may also be affected by various other factors that influence $\mathrm{Hg}$ bioavailability 
across landscapes. Previous work linked latitude with increased Hg biomagnification in aquatic food webs (Lavoie et al. 2013). Once in the body, organic MeHg is not readily excreted. Its tendency to build up in tissues of a single organism over time (bioaccumulation) means that, following trophic interactions, the highest concentrations occur in upper trophic levels (biomagnification). Based upon a worldwide meta-analysis, Lavoie et al. (2013) suggested that Hg biomagnification may be greater in northern regions. Their study hypothesized various temperature-related factors that could be contributing to this latitudinal trend including slower rates of growth and decreased $\mathrm{Hg}$ excretion rates of aquatic organisms at colder temperatures, resulting in increased bioaccumulation of $\mathrm{Hg}$ in tissues. Furthermore, simpler food webs at higher latitudes may limit prey choice for higher trophic level consumers increasing $\mathrm{Hg}$ transfer efficiency along a given food chain (Lavoie et al. 2013). It has also been previously noted that higher latitudes serve as a sink for airborne volatile contaminants through various atmospheric migration processes, such as the "grasshopper effect" (Wania and Mackay 1996).

Transport of elemental Hg from long-range or local sources may play a role in regulating its environmental bioavailability; however previous studies found that methylation rates were more important than inorganic $\mathrm{Hg}$ loading when determining fish MeHg exposure (Eagles-Smith et al. 2016). Under organic-rich, anaerobic conditions, sulfur-reducing bacteria mediate the transformation of inorganic $\mathrm{Hg}$ to organic $\mathrm{MeHg}$. Higher methylation rates linked to enhanced bacterial activity have been observed under low $\mathrm{pH}$ and high levels of dissolved organic carbon (Ullrich et al. 2001). Wetlands are a particularly important site for $\mathrm{MeHg}$ production in aquatic systems, with high methylation rates observed in various wetland ecosystems, including boreal forests (St Louis et al. 
1994) and tropical floodplains (Lazaro et al. 2016). As such, Hg trends in the PeaceAthabasca Delta may be reflecting environmental conditions favorable for $\mathrm{Hg}$ methylation to a greater degree than $\mathrm{Hg}$ transport in that region.

To investigate spatial patterns of $\mathrm{Hg}$ in the environment, I collected eggs of various gull species from breeding colonies located along a 14 degree latitudinal gradient in Alberta, Saskatchewan, and Northwest Territories (Table 1.1). When conducting such spatial comparisons, it becomes important to consider potential differences in laying bird trophic position across sites. For example, gulls have a dietary preference for fish but if fish availability is constrained, they will consume a variety of food types, including terrestrial prey and anthropogenic food sources (Hebert et al. 1999). Such variability in diet composition will affect the trophic position of the laying female, influencing exposure to biomagnifying contaminants and resultant deposition of contaminants into eggs. A routine method to assess dietary influence on contaminant trends is through the use of stable nitrogen isotopes.

\section{Techniques in Stable Nitrogen Isotope Analysis}

Stable nitrogen isotope analysis $\left({ }^{15} \mathrm{~N}\right.$ and $\left.{ }^{14} \mathrm{~N}\right)$ of bulk tissue is routinely used to evaluate organism trophic position (Kelly 2000; Post 2002; Layman et al. 2012). Natural elements can occur in various stable, i.e. non-radioactive, forms, or isotopes, depending on the number of neutrons in the nucleus. Because neutrons have mass but do not carry a charge, isotopes of the same element are chemically identical but possess kinetic properties different enough for isotopic fractionation to occur during biochemical reactions. For example, during waste production (e.g. uric acid in birds) the lighter ${ }^{14} \mathrm{~N}$ isotope is 
preferentially excreted while the heavier ${ }^{15} \mathrm{~N}$ isotope is preferentially retained. This leads to a predictable step-wise increase in the ratio of the heavier to light isotope with increasing trophic level. Nitrogen isotope data are usually expressed in delta notation $\left(\delta^{15} \mathrm{~N}\right)$ with delta values calculated according to the formula:

$$
\delta^{15} \mathrm{~N}(\%)=\left[\left(\mathrm{R}_{\text {sample }} / \mathrm{R}_{\text {standard }}\right)-1\right] * 1000
$$

where $\mathrm{R}$ is the ratio of the heavy to light isotope in the sample and standard reference material, i.e. atmospheric nitrogen (Dawson and Brooks 2001). In general, $\delta^{15} \mathrm{~N}$ values increase 3-4\%o with each trophic transfer (Peterson and Howarth 1987). For bird eggs, greater $\delta^{15} \mathrm{~N}$ values are expected to be found in eggs laid by females occupying higher trophic positions. However, spatial differences in nitrogen isotope baselines associated with the nitrogen being incorporated into the base of food webs complicate interpretation of bulk $\delta^{15} \mathrm{~N}$ (i.e. one $\delta^{15} \mathrm{~N}$ value generated from the analysis of a whole tissue sample) values across sites. For example, dabbling duckling feathers collected across western Canada exhibited a wide range of $\delta^{15} \mathrm{~N}$ values $(17.6 \%$ ) despite having similar feeding behaviours (Hebert and Wassenaar 2001). These large inter-site differences likely reflected a variety of agricultural practices, land use activities and different sources of nitrogen across sites. $\delta^{15} \mathrm{~N}$ associated with natural fertilizers (animal manure) typically exhibit higher values compared to synthetic fertilizers (Hebert and Wassenaar 2001). Anthropogenic nitrogen entering aquatic ecosystems as runoff is one possible factor that complicates the use of stable nitrogen isotope tracers. Isotope values can also vary across sites due to phytoplankton community composition, nutrient utilization and biological transformation of these nutrients (Altabet 2001; Karsch et al. 2003; Tamelander et al. 2009). Spatial differences or temporal shifts in nitrogen isotope baselines associated with 
nitrogen incorporated into the base of food webs at individual sampling locations must therefore be considered (Post 2002). This is often addressed by measuring $\delta^{15} \mathrm{~N}$ values in primary invertebrate consumers, such as filter-feeding molluscs (Cabana and Rasmussen 1994) or by examining stomach contents of the monitored species (Hyslop 1980). These methods come with their own sets of limitations, i.e. they make assumptions about food web connectivity between primary consumers and top predators, or they may offer only a snapshot of an organism's diet. Also problematic is when $\delta^{15} \mathrm{~N}$ values are being measured in archived samples for which no "baseline" food web samples are available. In this situation, other methods for assessing baseline $\delta^{15} \mathrm{~N}$ values must be used.

To circumvent the above issues, I use a novel method for generating both baseline and trophic position $\delta^{15} \mathrm{~N}$ values from individual samples using compound-specific stable nitrogen isotope analysis of individual amino acids (AA-CSIA). Source amino acids (AA) retain isotopic signatures found at the base of the food web because their amine groups undergo minimal transamination/deamination reactions in consumers providing a proxy for evaluating isotopic baselines (Chikaraishi et al. 2007). Trophic AA undergo nitrogen isotope fractionation and are used for defining consumer trophic position (Chikaraishi et al. 2009). These differences among AA have been found to be consistent among various taxa (McClelland and Montoya 2002; Chikaraishi et al. 2007, 2009; McCarthy et al. 2007; Bradley et al. 2015; Nielsen et al. 2015), including birds (Lorrain et al. 2009; McMahon et al. 2015; Hebert et al. 2016). Despite the utility of the AA-CSIA approach as outlined in the above studies, its application in environmental contaminant studies is still in its infancy. My work provides the first example demonstrating the utility of this analytical approach to evaluating spatial trends in $\mathrm{Hg}$ levels in wildlife tissues. 


\section{Current Study}

My work focuses on using colonial waterbird eggs, specifically gulls, as indicators of $\mathrm{Hg}$ availability in the environment. Samples from twelve sites (Figure 1.1) in Alberta, Saskatchewan, and Northwest Territories, spanning a 14 degree latitudinal gradient, were collected and analyzed for total Hg. These results were used to assess spatial patterns in egg $\mathrm{Hg}$ levels and to explore possible factors regulating these patterns, i.e. latitudinal and watershed influences. Logistical issues required me to collect eggs from those areas at similar times, even though breeding would have commenced earlier at more southerly sites. For this reason, eggs were at different stages of incubation when collected; therefore, the degree to which stage of incubation may have affected egg $\mathrm{Hg}$ concentrations required study.

In Chapter 2, I describe the utility of colonial waterbird eggs as indicators of environmental contaminants. I address a number of issues that may affect the degree to which gull eggs are an appropriate matrix for assessing environmental contaminant availability. I pay particular attention to determining the influence of stage of incubation on egg $\mathrm{Hg}$ concentrations. I accomplish this by conducting controlled egg dosing experiments. I injected chicken eggs with a known amount of $\mathrm{MeHg}$ and artificially incubated them. Then, I processed the egg contents and prepared the samples for $\mathrm{Hg}$ analysis. Finally, I conducted the $\mathrm{Hg}$ analysis on the samples at the National Wildlife Research Centre (NWRC, Ottawa). The resulting data were used to determine the influence of stage of incubation on dry weight egg $\mathrm{Hg}$ concentrations. In this chapter, I also develop and evaluate a method for adjusting egg $\mathrm{Hg}$ concentrations for stage of development based on morphological parameters of individual eggs. 
Chapter 3 focuses on evaluating spatial patterns of egg $\mathrm{Hg}$ levels assessed over 12 sites in Alberta, Saskatchewan, and Northwest Territories. I collected wild gull eggs in the field, processed the egg contents, and encapsulated individual and pooled samples for isotope analysis. I also conducted the $\mathrm{Hg}$ analysis at NWRC. The encapsulated individual samples were submitted for stable isotope analysis to the G.G. Hatch Laboratory at the University of Ottawa. I examine relationships between egg $\mathrm{Hg}$ levels and latitude as well as the impact of trophic position on spatial patterns in egg $\mathrm{Hg}$ levels. I accomplish the latter by applying amino acid-compound specific stable nitrogen isotope analysis (AACSIA). Compound-specific stable isotope analysis was conducted at the University of Hawaii using pooled samples. I present a detailed description of the AA-CSIA approach, its utility and drawbacks. The results of the spatial analysis are discussed within the context of latitudinal trends, proximity to $\mathrm{Hg}$ sources and potential drivers of $\mathrm{Hg}$ methylation.

Chapter 4 provides an integrative summary of my results, conclusions and novelty of the work presented here. Future directions and application of AA-CSIA, particularly in the context of environmental contaminants research in the oil sands region, are discussed. 


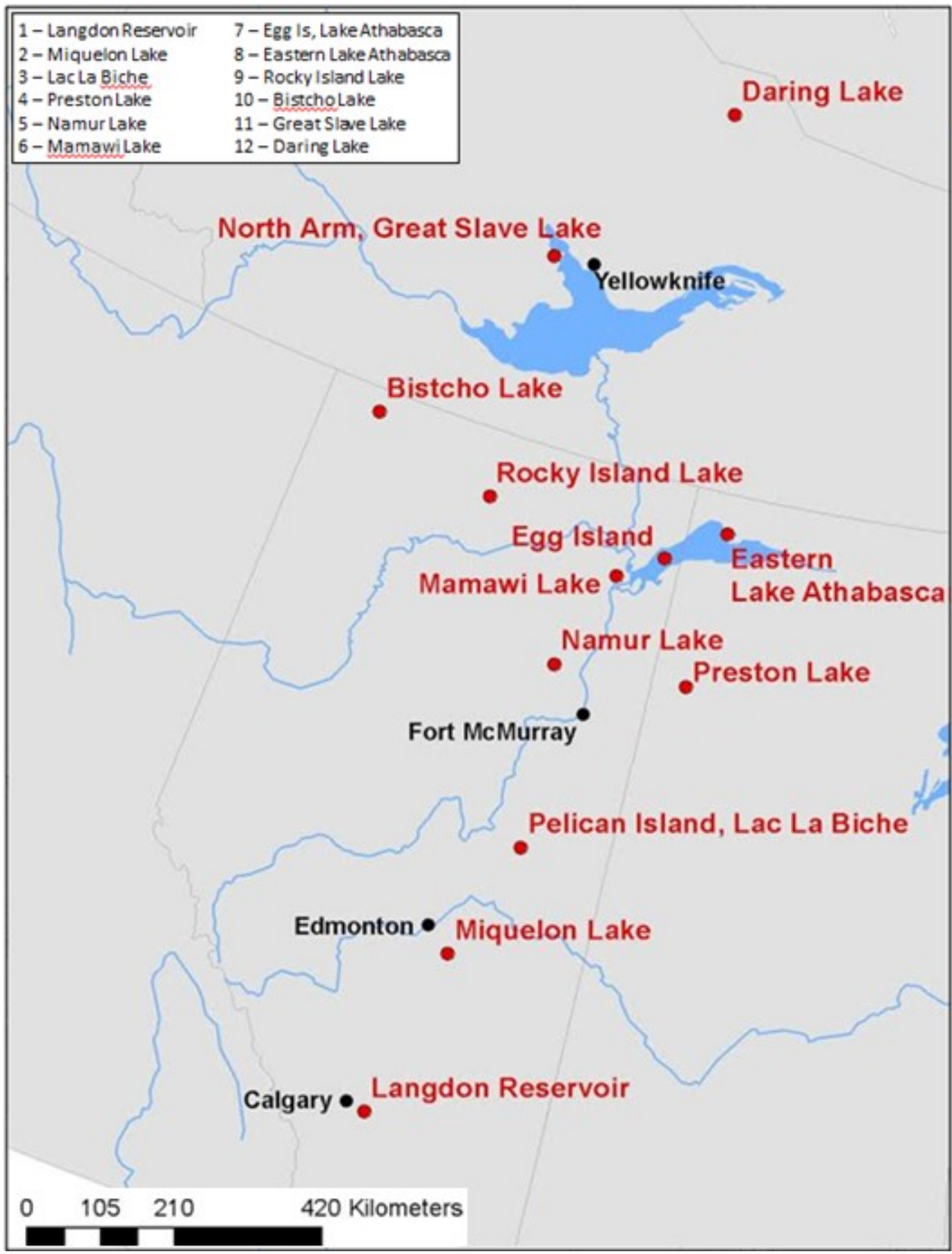

Figure 1.1 Gull eggs were collected in 2014 and 2015 from the 12 numbered locations spanning a 14 degree latitudinal gradient. Samples from these sites were used to examine spatial patterns in egg mercury levels. 
Table 1.1 Summary of collection sites with number of eggs collected. Stage of incubation is the average stage of development of eggs collected at each site; it is expressed as a proportion of the period necessary for completion of incubation. Incubation periods are species-specific: Herring Gull (HERG) $=28$ days, Ring-Billed Gull $($ RBGU $)=27$ days, California Gull $(\mathrm{CAGU})=26$ days $($ Birds of North America, online $)$.

\begin{tabular}{|c|c|c|c|c|c|}
\hline Location & Degree of Latitude & Year & Species & \# Samples & Stage of Incubation \\
\hline \multirow{2}{*}{1 - Langdon Reservoir } & \multirow{2}{*}{50.9} & 2014 & \multirow{2}{*}{ CAGU } & 15 & 0.25 \\
\hline & & 2015 & & 15 & 0.13 \\
\hline \multirow{2}{*}{2 - Miquelon Lake } & \multirow{2}{*}{53.3} & 2014 & \multirow{2}{*}{$\mathrm{CAGU}$} & 15 & 0.60 \\
\hline & & 2015 & & 15 & 0.79 \\
\hline \multirow{4}{*}{3 - Lac La Biche } & \multirow{4}{*}{54.8} & \multirow{2}{*}{2014} & CAGU & 15 & 0.69 \\
\hline & & & HERG & 15 & 0.58 \\
\hline & & \multirow{2}{*}{2015} & CAGU & 15 & 0.74 \\
\hline & & & HERG & 15 & 0.74 \\
\hline \multirow{2}{*}{4 - Preston Lake } & \multirow{2}{*}{57.4} & 2014 & \multirow{2}{*}{ RBGU } & 15 & 0.18 \\
\hline & & 2015 & & 15 & 0.15 \\
\hline \multirow{4}{*}{5 - Namur Lake } & \multirow{4}{*}{57.5} & \multirow{2}{*}{2014} & CAGU & 15 & 0.59 \\
\hline & & & HERG & 10 & 0.56 \\
\hline & & \multirow{2}{*}{2015} & CAGU & 15 & $\mathrm{~N} / \mathrm{A}$ \\
\hline & & & HERG & 14 & 0.27 \\
\hline \multirow{2}{*}{6 - Mamawi Lake } & \multirow{2}{*}{58.6} & 2014 & \multirow{2}{*}{ RBGU } & 10 & 0.14 \\
\hline & & 2015 & & 10 & 0.85 \\
\hline \multirow{4}{*}{$\begin{array}{l}7 \text { - Egg Is, } \\
\text { Lake Athabasca }\end{array}$} & \multirow{4}{*}{59.0} & \multirow{2}{*}{2014} & CAGU & 10 & 0.68 \\
\hline & & & HERG & 5 & 0.53 \\
\hline & & \multirow{2}{*}{2015} & CAGU & 10 & 0.73 \\
\hline & & & HERG & 3 & 0.80 \\
\hline \multirow{4}{*}{$\begin{array}{l}8 \text { - Eastern } \\
\text { Lake Athabasca }\end{array}$} & \multirow{4}{*}{59.2} & \multirow{2}{*}{2014} & CAGU & 14 & 0.23 \\
\hline & & & HERG & 17 & 0.69 \\
\hline & & \multirow{2}{*}{2015} & CAGU & 15 & 0.38 \\
\hline & & & HERG & 15 & 0.66 \\
\hline 9 Rocky Island I ake & 502 & 2014 & HFRG & 9 & 0.54 \\
\hline 9 - Rоску Island Lake & 39.2 & 2015 & HERU & 9 & 0.31 \\
\hline & & & CAGU & 15 & 0.58 \\
\hline 10 Dictsh I le & 507 & 2014 & HERG & 15 & 0.43 \\
\hline 10 - Bistcno LaKe & 59.1 & 2015 & CAGU & 15 & 0.30 \\
\hline & & 2015 & HERG & 15 & 0.23 \\
\hline & & 2014 & & 14 & 0.69 \\
\hline 11 -Great Slave Lake & 62.8 & 2015 & HERG & 15 & 0.55 \\
\hline & & 2014 & & 6 & $\mathrm{~N} / \mathrm{A}$ \\
\hline 12 - Daring Lake & 64.9 & 2015 & HERG & 5 & 0.75 \\
\hline & & & Total: & 431 & \\
\hline
\end{tabular}




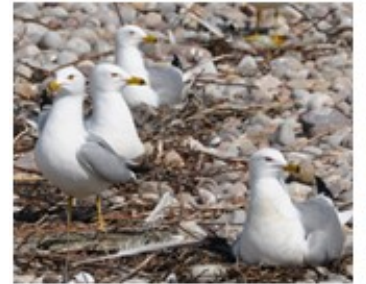

Ring-billed

Gull

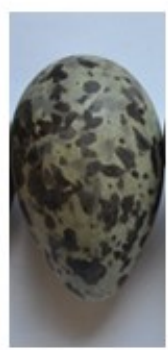

RBGU

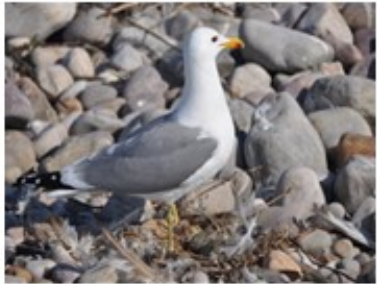

California

Gull

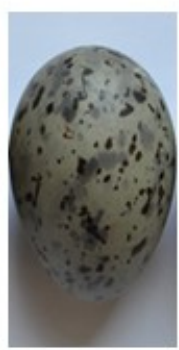

CAGU

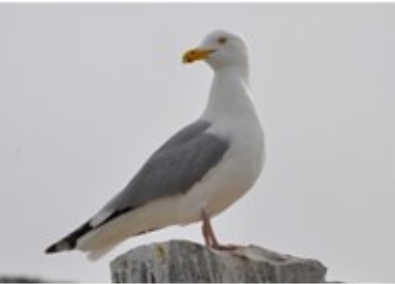

Herring

Gull

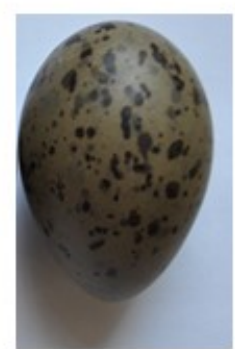

HERG

Figure 1.2 Colonial waterbird study species.

RBGU - Ring-Billed Gull (Larus delawarensis)

CAGU - California Gull (Larus californicus)

HERG - Herring Gull (Larus argentatus smithsonianus) 
CHAPTER TWO

\section{UTILITY OF EGGS AS BIOINDICATORS \\ AND \\ INFLUENCE OF STAGE OF DEVELOPMENT \\ ON EGG MERCURY CONCENTRATIONS}




\section{Introduction}

Colonial waterbirds are used as indicator species in a variety of environmental monitoring programs (Hebert et al. 1999; Burgess et al. 2013; Braune et al. 2015; Elliott and Elliott 2016). Their utility in this regard is recognized for several reasons. These birds are widely distributed, long-lived and colonial, thus facilitating geographical comparisons and population assessments. Herring Gulls (Larus argentatus smithsonianus), for example, have been used since the 1970 s as sentinels in contaminant monitoring programs on the Great Lakes (Hebert et al. 1999). Using Herring Gull eggs, sources and dynamics of various organic environmental pollutants such as mirex, polychorinated-dibenzodioxins, polychorinated-dibenzofurans, and polychlorinated biphenyls have been established for that region (Hebert et al. 1999). Furthermore, as top predators in their respective food webs, gulls are useful for assessing trends of bioaccumulating and biomagnifying contaminants, such as mercury $(\mathrm{Hg})$. Adverse reproductive effects associated with $\mathrm{Hg}$ exposure have been observed in multiple taxa, including birds (Wolfe et al. 1998). Given that impaired reproduction is a common toxicological endpoint associated with $\mathrm{Hg}$ exposure in birds (Scheuhammer et al. 2007), many studies focus on bird eggs to assess the environmental availability of $\mathrm{Hg}$ and its potential toxic effects (Evers et al. 2003; Hebert et al. 2013).

Inorganic $\mathrm{Hg}$ enters aquatic ecosystems from natural and anthropogenic sources. Bacterial methylation of $\mathrm{Hg}$ results in the formation of methylmercury $(\mathrm{MeHg})$ which biomagnifies, thereby reaching highest concentrations in top predators. $\mathrm{MeHg}$ is of particular concern because it is a potent neurotoxin and not readily excreted from the body (Clarkson 1992). In mammals, $\mathrm{MeHg}$ binds to sulfhydryl groups of proteins, making a 
complex that readily crosses the placenta, leading to accumulation of MeHg in the embryo (Scheuhammer et al. 2007). In birds, eggs are an important path of excretion of $\mathrm{MeHg}$ from adult females (Heinz 1979). A positive correlation between $\mathrm{Hg}$ concentrations in eggs and the internal tissues of laying females has been recorded for bird species of different feeding guilds, including fish-eating birds (Evers et al. 2003; Ackerman et al. 2016). Hg acquired through the diet of a laying female is rapidly transferred to her eggs (Heinz 2009b), with the majority of MeHg deposited into the albumen (Heinz and Hoffmann 2004). Controlled feeding studies in chickens (Gallus gallus domesticus) found that transfer of dietary MeHg to eggs occurred within two days after oral administration, peaking in concentration at day three (Kambamanoli-Dimou et al. 1991). Various tissues can be sampled to assess $\mathrm{Hg}$ content, including liver, blood, muscle and feathers

(Scheuhammer et al. 2007); eggs have the advantage of being relatively easy to collect and transport, and their collection has a minimal impact on bird populations as opposed to the sacrifice of adult birds. Here, I outline factors that could influence the use of colonial waterbird eggs to monitor pollutants in the environment. In particular, I investigate whether stage of incubation affects egg Hg levels and suggest a mathematical approach for adjusting $\mathrm{Hg}$ levels for stage of development.

\section{Gull Eggs as Local Indicators}

In order to accurately assess spatial patterns and potential sources of contaminants such as $\mathrm{Hg}$, it is important to ensure that concentrations in eggs reflect local sources. This is particularly important for migrant birds that may be carrying contaminant loads from their overwintering grounds to their breeding grounds. One way to assess the origin of 
contaminants is to compare isotopic signatures in eggs with expected signatures associated with breeding and wintering grounds. The isotopic signatures in consumer's tissues ultimately represent those in their diets (DeNiro and Epstein 1978, 1981) allowing us to evaluate the nutrient transfer in different biomes and identify the relative importance of endogenous (body reserves) and exogenous (dietary intake) nutrient resources for reproduction. The common typology for these life strategies among birds is "capital" and "income" breeding. Capital breeding refers to the accumulation of nutrient reserves in the body of the female and these reserves are used for egg formation; income breeders use recently ingested food for egg formation without reliance on stored reserves (Thomas 1988; Stephens et al. 2009). In nature, these two descriptions represent theoretical extremes with actual strategies falling somewhere along a continuum between the two. Domestic hens, for example, deposit lipids into growing eggs from body reserves while supplementing protein from increased dietary intake of invertebrates during the egg formation period (Gill 2007). Gulls typically align closer to the income breeder strategy, allocating exogenous nutrients to reproduction (Bond and Diamond 2010; Hebert et al. 2016).

Specific chemical tracers in the tissues of birds can help to elucidate the origin of nutrients incorporated into tissues, including eggs. Sulfur isotopes $\left({ }^{34} \mathrm{~S} /{ }^{32} \mathrm{~S}\right.$, expressed as $\delta^{34} \mathrm{~S}$ ) are useful in discriminating between marine and freshwater food sources because of the large differences in $\delta^{34} \mathrm{~S}$ values between these environments (Connolly et al. 2004). This difference stems from differing sulfur sources and sulfur assimilation pathways in continental vegetation versus marine plankton and seaweeds (Fry 2006). Sulfur isotopes are typically considered more useful than carbon isotopes to infer nutrient sources for birds known to migrate between marine and inland biomes because its interpretation is not 
confounded by trophic fractionation (Hobson et al. 1997; MacAvoy et al. 2000). Lott et al. proposed a threshold for inland $\delta^{34} \mathrm{~S}$ values of $10 \%$; anything greater suggested reliance on marine prey (Lott et al. 2003). Isotopic studies looking at both egg content and natal down in colonial waterbirds and waders concluded that females relied primarily on local food sources for egg formation (Hobson et al. 1997, 2004; Klaassen 2001; Morrison and Hobson 2004). Given that $\mathrm{Hg}$ is readily transferred to eggs (Kambamanoli-Dimou et al. 1991; Heinz et al. 2009b) and is derived from dietary intake and assimilation of local prey, egg $\mathrm{Hg}$ levels likely reflect local $\mathrm{Hg}$ availability. Here, I provide sulfur isotope data for eggs collected from 12 gull colonies located in freshwater lakes across a 14 degree latitudinal gradient in western Canada to determine sources of nutrients used for egg formation. These data are informative regarding the degree to which gull eggs reflect local bioavailability of $\mathrm{Hg}$ at breeding colonies. Gull species included in my research are thought to overwinter primarily in marine waters along the Pacific coast of North America (Birds of North America, online). During inland migration and breeding, they switch to freshwater/terrestrial food sources. As such, being income breeders, I expect $\delta^{34} \mathrm{~S}$ signatures in eggs of gulls to reflect isotope values in local freshwater food sources obtained near their breeding colonies with egg $\delta^{34} \mathrm{~S}$ values falling below Lott's proposed marine $\delta^{34} \mathrm{~S}$ threshold of $10 \%$.

\section{Total Mercury vs Methylmercury Concentrations}

Organic $\mathrm{MeHg}$, is retained within tissues and is thus the form most relevant to avian ecotoxicology. Often, total mercury (THg, sum of both organic and inorganic forms) is used as a proxy for $\mathrm{MeHg}$ because it is easier to determine analytically and is less 
expensive. For my work, this approach is appropriate as Ackerman et al. (2013) found that for 22 different bird species over $96 \%$ of $\mathrm{Hg}$ in eggs was in the organic $\mathrm{MeHg}$ form (Ackerman et al. 2013).

\section{Laying Sequence}

The protocol for field collections of gull eggs involved random sampling of a single egg from nests containing complete clutches (typically three eggs; Burgess et al. 2013). This was done systematically across all the colonies I sampled. However, it is important to consider possible intra-clutch variation in egg $\mathrm{Hg}$ levels. Previous studies have demonstrated that laying order influences $\mathrm{Hg}$ concentrations, with as much as a $24-48 \%$ decline in egg $\mathrm{Hg}$ concentrations from first to last laid eggs for seabird and duck species (Akearok et al. 2010). This could have serious implications for contaminant monitoring programs that use colonial waterbird eggs to track $\mathrm{Hg}$ levels, particularly across varying spatial and temporal scales. However, Ackerman et al. found that most variance in egg $\mathrm{Hg}$ concentrations came from between clutches, rather than within clutches (Ackerman et al. 2016). Furthermore, they conducted a collection simulation (randomly collecting 1 egg per clutch) and found that, to be within $20 \%$ of the actual population mean for egg $\mathrm{Hg}$ concentrations, it was sufficient to collect 14 eggs for a colony of 100 nests or less. For my study, 15 eggs were collected per species, per site, wherever available (Table 1.1). Since laying sequences were not known at time of collection, this was deemed a reasonable approach in my research and this factor was not considered further. 


\section{Stage of Development}

Collecting eggs from gull colonies along a latitudinal gradient or through time may result in samples being collected at various stages of incubation. For example, latitudinal collections done around the same time may result in eggs from southern sites being further developed than those from northern sites since initiation of breeding and laying is typically driven by photoperiod (Sharp 1996). As the egg progresses through development, it loses water through diffusion across the porous membrane of the eggshell resulting in a decrease in egg mass. Since levels of protein-bound $\mathrm{Hg}$ in tissues are reported as a concentration, most studies report egg Hg concentrations on a dry weight basis. The assumption is that, while water diffuses out of the egg as development progresses, the dry weight remains unchanged, leading to unbiased dry weight $\mathrm{Hg}$ concentrations regardless of incubation stage.

However, the assumption of unchanging egg dry mass deserves scrutiny when considering the physiology of a growing embryo. Lipids stored in the egg are catabolized to provide energy for the growing embryo with metabolic water being produced as a byproduct. Along with the water in the egg at the time of laying, this metabolic water diffuses out of the egg during incubation; as such, the diffused metabolic water can be considered as a fraction of solids consumed. Conversion of dry matter, i.e. lipid, to energy and metabolic water results in a relatively constant ratio of wet to dry mass in the egg over the course of development (Ar and Rahn 1980). However, most of the dry mass loss occurs post mid-incubation as the metabolic rate of the embryo greatly increases (Vleck et al. 1980). Changes in egg dry mass can therefore have a direct impact on Hg concentrations expressed on a dry weight basis if eggs are collected at various stages of incubation. 
To test the degree to which changes in egg dry weight may affect egg Hg levels throughout incubation, I conducted laboratory experiments using freshly laid, i.e. unincubated, chicken (Gallus gallus domesticus) eggs. I dosed the eggs with a known amount of MeHg, artificially incubated them and then sampled eggs at regular intervals to examine possible changes in dry weight $\mathrm{Hg}$ concentrations through incubation.

\section{Incubation Adjustment Factor}

Given that egg dry mass changes throughout incubation, objective comparison of samples across multiple sites based on dry weight concentrations may not be appropriate. To circumvent this issue, I examined the degree to which egg morphological measurements could be used as a means of adjusting egg $\mathrm{Hg}$ levels for stage of incubation. This approach is based on the initial specific gravity of eggs, which is highly conservative across multiple species regardless of relative yolk content, with an average value of approximately 1.0 $\mathrm{g} / \mathrm{cm}^{3}$ (Rahn and Paganelli 1989). Hence, egg contents mass can be predicted based upon the volume of an egg, e.g. $60 \mathrm{~cm}^{3}$ egg should have a mass of $60 \mathrm{~g}$ at the beginning of incubation (1:1 ratio). As incubation progresses, however, egg contents mass will decline resulting in an egg contents mass to volume ratio of less than 1.0. Because egg volume remains constant throughout incubation while egg contents mass decreases, it may be possible to use the ratio of mass to egg volume as a proxy for stage of incubation. Here, I investigate the utility of an incubation adjustment factor based upon egg contents mass and volume to adjust egg dry weight $\mathrm{Hg}$ concentrations for stage of incubation.

One way to validate the use of the incubation adjustment factor to account for stage of development effects on egg $\mathrm{Hg}$ concentrations is to examine the relationship between 
this factor and known incubation stage. Here, I examine the gull egg samples collected from the 12 sites in western Canada. I use morphological parameters (length, width, egg contents mass) to formulate the adjustment factor and examine its relationship with known incubation stage.

\section{Methods}

Gull Egg Collection and Processing

Eggs of Herring Gull (Larus argentatus smithsonianus), California Gull (L. californicus), and Ring-Billed Gull (L. delawarensis) were collected in 2014 and 2015 from 12 breeding colonies in Alberta, Saskatchewan and Northwest Territories, spanning a 14 degree latitudinal gradient (Figure 1.1). One egg was collected per nest, typically from a clutch of three eggs. A total of 15 eggs were collected per species/site where possible (Table 1.1). All eggs were marked in the field with an identifying code, stored in foamlined Pelican cases, and transported to Environment and Climate Change Canada's National Wildlife Research Centre (NWRC, Ottawa, Canada). All collections were made under the authority of appropriate permitting agencies and Animal Care Committees. Whole eggs were measured for physical parameters, i.e. total egg mass, maximum egg length, maximum egg breadth, and then opened in biosafety cabinets. The embryo's stage of development and egg contents mass were recorded at the time the eggs were opened. Egg contents (yolk and albumen) were homogenized together using an electric mixer and chemically clean techniques. Samples showing signs of embryonic development were frozen in liquid nitrogen and pulverized using a cryogenic ball-mill. Homogenates were aliquoted into acid-washed glass and polypropylene containers. Sub-samples of equal 
weight from the same site and same species were used to create pooled samples. All samples were stored at $-40^{\circ} \mathrm{C}$ prior to chemical analysis.

\section{Gull Eggs as Local Indicators}

Sulfur isotope analysis was performed on pooled egg samples from 2014 only (Table 2.1). Homogenates stored in polypropylene vials were freeze-dried for at least 48 hours using a Labconco FreezeZone 6 Litre Freeze Dry System (Model 77530). Freezedried homogenates $(\sim 1 \pm 0.2 \mathrm{mg})$ from each pool were encapsulated in tin and used for sulfur isotope measurements. $\delta^{34} \mathrm{~S}$ analyses were conducted at the University of Waterloo (Waterloo, Ontario, Canada) using continuous-flow isotope-ratio mass spectrometry (CFIRMS). The CFIRMS system was interfaced to a Carlo-Erba Elemental Analyzer (Thermo Electron Corporation, Milan, Italy) in sulfur mode. Stable sulfur isotope results were expressed in standard delta $(\delta)$ notation, relative to Canyon Diablo Troilite reference material.

\section{Stage of Development}

I measured background levels of THg in 10 freshly laid chicken eggs obtained from the Canadian Food Inspection Agency (Ottawa, ON).

To test the degree to which stage of incubation affected dry weight $\mathrm{Hg}$ concentrations, I conducted two controlled $\mathrm{Hg}$ injection studies. A total of 55 chicken eggs were procured from the Canadian Food Inspection Agency (Ottawa, ON). Forty-nine of these eggs were viable and were included in the experiments. Each egg was weighed and 
candled to determine the location of the air sac. Experimental protocols were based on those of Heinz et al. (2006) with minor variations as outlined below.

For experiment 1, a total of 33 eggs of similar mass were used. A small hole was drilled through the eggshell over the air sac, wide enough to fit a pipette tip. Each egg sample was administered an equal dose of $50 \mu \mathrm{L}$ methylmercury (II) chloride, dissolved in dimethyl sulfoxide, with each egg receiving approximately $5 \mu \mathrm{g}$ of MeHg. The dosage was based on a desired $\mathrm{Hg}$ concentration of $100 \mathrm{ng} \cdot \mathrm{g}^{-1}$ of $\mathrm{Hg}$ per $50 \mathrm{~g}$ egg which ensured detectability of $\mathrm{Hg}$ while remaining under thresholds associated with toxic effects of $\mathrm{Hg}$ (Heinz et al. 2006; Braune et al. 2012). AirPore ${ }^{\mathrm{TM}}$ tape was used to cover the drill holes, allowing for free gas exchange. Eggs rested sideways for an hour at room temperature to allow the $\mathrm{Hg}$ dose to diffuse through the egg contents. Each egg was then placed in an artificial incubator (Petersime) held at $37.5^{\circ} \mathrm{C}$ and $60 \pm 5 \%$ relative humidity with an egg turning frequency of 2 hours. The samples were left untouched until their randomly assigned designated extraction day $(0,3,6,9,12,15$, or 18$)$. Twenty-one days are required for complete incubation of chicken eggs. Eggs were removed from the incubator on their assigned day, weighed and the contents extracted in a biosafety cabinet under chemicallyclean conditions. For eggs at later stages of development, i.e. day 18, decapitation was carried out following protocols sanctioned by an Animal Care and Ethics Committee. Due to infertility upon opening, the total number of viable eggs was reduced to 29 . Homogenization and freeze-drying of egg contents followed the same techniques as outlined for gull eggs above.

For $\mathrm{Hg}$ content analysis, approximately $20 \mathrm{mg}$ of dried egg contents were aliquotted onto nickel boats and delivered by autosampler to the furnace of an Advanced Mercury 
Analyzer (AMA-253, Altec, Czech Republic) for chemical and thermal decomposition. Following decomposition, the resulting vapor was carried by ultra-pure oxygen to an amalgamator which selectively trapped $\mathrm{Hg}$. Total collected $\mathrm{Hg}$ was released to the Atomic Absorption Spectrometer for detection measured at $253.65 \mathrm{~nm}$. In eggs, approximately $96 \%$ of total $\mathrm{Hg}$ is in the organic MeHg form (Ackerman et al. 2013) so measuring THg is an efficient, cost-effective way to assess MeHg levels in eggs. Quality assurance methods involved the use of certified reference material (OT1566b, TORT-3, DOLT-4, IAEA-407, BCR-463) and sample duplicates. THg concentrations measured in all the samples were within the concentration ranges of certified reference materials. Limit of detection for $\mathrm{THg}$ was $0.006 \mu \mathrm{g} \cdot \mathrm{g}^{-1}$ (dry weight).

Non-parametric statistics were used to examine the effect of stage of development on egg concentrations (Spearman's correlation, $\mathrm{r}_{\mathrm{s}}$ ) and to examine differences in egg $\mathrm{Hg}$ concentrations at specific stages of incubation (Kruskal-Wallis test, followed by post-hoc comparison of mean ranks). Based upon the results of this experiment, a second incubation experiment (day $0, n=10$; day $18, n=10$ ) was conducted using identical protocols as described above. In addition, morphological parameters (egg length, width, egg contents mass) were recorded. Differences in egg $\mathrm{Hg}$ concentrations at the beginning (day 0) and end (day 18) of the second experiment were tested using parametric statistics (two-tailed ttest). In addition, egg $\mathrm{Hg}$ data from the second experiment were adjusted for stage of incubation according to the following equation:

Adjusted $[\mathrm{Hg}]=[\mathrm{Hg}] \mathrm{x}$ incubation adjustment factor

The calculation for the incubation adjustment factor is described in the next section, with volume calculated using a formula developed by Narushin (2005) for chicken eggs: 
Egg volume $\left(\mathrm{cm}^{3}\right)=0.525\left(\right.$ length $\mathrm{x}$ width $\left.{ }^{2}\right) / 1000$

Differences in adjusted $\mathrm{Hg}$ concentrations were tested using t-tests. All statistical analyses were conducted using Statistica Ver. 12 (StatSoft, 2013).

\section{Incubation Adjustment Factor}

To validate the use of an adjustment factor to account for stage of development effects on egg $\mathrm{Hg}$ concentrations, I first confirmed that the adjustment factor was related to incubation stage using data from the gull eggs collected in 2014 and 2015. When these eggs were opened, stage of development, i.e. day of incubation, was estimated for each egg. Using these estimates, I calculated the proportion of the total incubation period reached by individual eggs at the time of their collection. Day of incubation could only be estimated using viable embryos, so egg contents with physiological anomalies (e.g. addled) were omitted. Samples with shell mold or other defects on the inside of the egg were omitted as well since they could have interfered with gas diffusion. Incubation period durations for the study species: Herring Gull (28 days), California Gull (27 days), RingBilled Gull (26 days) were taken from the literature (Birds of North America, online). An incubation adjustment factor was calculated for each gull egg sample as follows:

Incubation adjustment factor $=$ egg contents mass $(\mathrm{g}) /$ egg volume $\left(\mathrm{cm}^{3}\right)$

Egg volume was calculated using a formula developed for Herring Gulls (Harris 1964):

Egg volume $\left(\mathrm{cm}^{3}\right)=0.476\left(\right.$ length $\mathrm{x}$ width $\left.{ }^{2}\right) / 1000$

Linear regression was used to examine the relationship between incubation adjustment factor and estimated stage of incubation for gull eggs. 


\section{Results}

\section{Sulfur Isotopes}

$\delta^{34} \mathrm{~S}$ values in pooled egg homogenates showed a range of values but all values were below $10 \%$ (Table 2.1). Highest values were found in Herring Gull eggs from Great Slave Lake (9.7 \%o). Lowest values were found in samples from Bistcho Lake, for both California Gull eggs (-10.9\%o) and Herring Gull eggs (-10.5 \%o). Mean values at remaining sites ranged between $-7.2 \%$ and $4.2 \%$.

Table 2.1. $\quad \delta^{34} \mathrm{~S}$ values in egg pools of Herring Gulls (HERG), California Gulls (CAGU) and Ring-Billed Gulls (RBGU) collected in 2014. Site numbers correspond to those in Figure 1.1.

\begin{tabular}{|c|c|c|c|c|}
\hline Site & $\begin{array}{l}\text { Province/ } \\
\text { Territory }\end{array}$ & Degrees of Latitude & Species & $\delta^{34} \mathrm{~S}(\%)$ \\
\hline 1 - Langdon Reservoir & $\mathrm{AB}$ & 50.9 & CAGU & 1.2 \\
\hline 2 - Miquelon Lake & $\mathrm{AB}$ & 53.3 & CAGU & -0.7 \\
\hline \multirow{2}{*}{3 - Lac La Biche } & \multirow{2}{*}{$\mathrm{AB}$} & \multirow{2}{*}{54.8} & HERG & -1.3 \\
\hline & & & CAGU & -1.1 \\
\hline 4 - Preston Lake & $\mathrm{AB}$ & 57.4 & RBGU & 3.8 \\
\hline \multirow{2}{*}{5 - Namur Lake } & \multirow{2}{*}{$\mathrm{AB}$} & \multirow{2}{*}{57.5} & HERG & -2.4 \\
\hline & & & CAGU & -0.8 \\
\hline 6 - Mamawi Lake & $\mathrm{AB}$ & 58.6 & RBGU & -1.4 \\
\hline \multirow{2}{*}{7 - Egg Is, Lake Athabasca } & \multirow{2}{*}{$\mathrm{AB}$} & \multirow{2}{*}{59.0} & HERG & 1.9 \\
\hline & & & CAGU & 2.6 \\
\hline \multirow{2}{*}{8 - Eastern Lake Athabasca } & \multirow{2}{*}{ SK } & \multirow{2}{*}{59.2} & HERG & 2.6 \\
\hline & & & CAGU & 4.1 \\
\hline 9 - Rocky Island Lake & $\mathrm{AB}$ & 59.2 & HERG & -7.2 \\
\hline \multirow{2}{*}{10 - Bistcho Lake } & \multirow{2}{*}{$\mathrm{AB}$} & \multirow{2}{*}{59.7} & HERG & -10.5 \\
\hline & & & CAGU & -10.9 \\
\hline 11 - Great Slave Lake & NT & 62.8 & HERG & 9.7 \\
\hline 12 - Daring Lake & NT & 64.9 & HERG & 4.2 \\
\hline
\end{tabular}




\section{Stage of Development}

Background Hg levels in CFIA chicken eggs were below the limit of detection for $\mathrm{Hg}$.

For experiment 1, a total of 33 chicken eggs were assigned to seven subgroups to be sampled at different stages of incubation. Of these 33 eggs, four were infertile upon opening and removed from the experiment (two from day 2 ( 0.14 of total incubation period) and one from each of day 6 (0.29 of total incubation period) and day 12 (0.57 of total incubation period)). All other samples reached their assigned stage of incubation. $\mathrm{Hg}$ concentrations in all samples were above the detection limit for $\mathrm{Hg}$. Egg $\mathrm{Hg}$ concentration data did not meet homogeneity of variance assumptions (Levene $F_{6,22}=6.0, P<0.001$ ) necessary for the use of parametric statistics so nonparametric statistics were used to assess changes in egg Hg through development.

Nonparametric correlation analysis revealed a significant relationship between $\mathrm{Hg}$ concentrations in eggs and stage of incubation $\left(r_{s}=0.55, n=29, P<0.05\right.$; Figure 2.1). Significant differences in egg Hg levels at different stages of development (Kruskal-Wallis test, $H=14.8, d f=6, P=0.02$ ) were observed. Post-hoc comparisons of mean ranks revealed statistically greater $\mathrm{Hg}$ concentrations in eggs collected at the latest stage of development ( $86 \%$ of total incubation period) compared to mid-incubation ( $43 \%$ of total incubation period, $P=0.02) ; \mathrm{Hg}$ levels in eggs at $29 \%$ total incubation period were almost statistically different from late stage incubation eggs $(P=0.07$; Figure 2.1). Other time points showed no statistically significant differences in egg $\mathrm{Hg}$ concentrations $(P>0.05)$. The large standard deviation for samples at $14 \%$ of the total incubation period could be explained by leakage of the $\mathrm{MeHg}$ dose solution upon injection for one of the samples. 
The lack of statistically significant differences among periods reflected the relatively low sample sizes within periods. To investigate this further, I conducted a power analysis assessing the probability of detecting a significant difference in egg $\mathrm{Hg}$ concentrations between the beginning ( $0 \%$ of total incubation period) and near the end of incubation $(86 \%$ total incubation period). This analysis revealed relatively low power (2-tailed t-test, power $=0.34$ ) associated with my sample sizes for experiment 1 . Based on the data from experiment 1 and this power analysis, adequate statistical power to detect inter-period differences could be provided with an $n=10$ (2-tailed t-test, power $=0.80)$. Therefore, I repeated the experiment injecting 20 chicken eggs with the same dose of MeHg but focused on examining egg $\mathrm{Hg}$ concentrations at the beginning (day $0, n=10$ ) and near the end of incubation (day 18, $n=10$ ). Egg $\mathrm{Hg}$ data from this experiment met assumptions underlying parametric statistics (Levene $F_{1,18}=0.14, P=0.7$; Shapiro-Wilks $W=0.96, P=0.57$ ) so a t-test was used to examine differences in egg $\mathrm{Hg}$ concentrations at the beginning and end of incubation.

Dry weight $\mathrm{Hg}$ concentrations in eggs at the late stage of incubation were significantly greater than eggs in the early stage of incubation (two-tailed t-test, $t=7.1, d f$ $=18, P<0.0001$; Figure 2.2). There was a $14.5 \%$ increase in dry weight $\mathrm{Hg}$ concentrations near the end of incubation compared to unincubated eggs. 


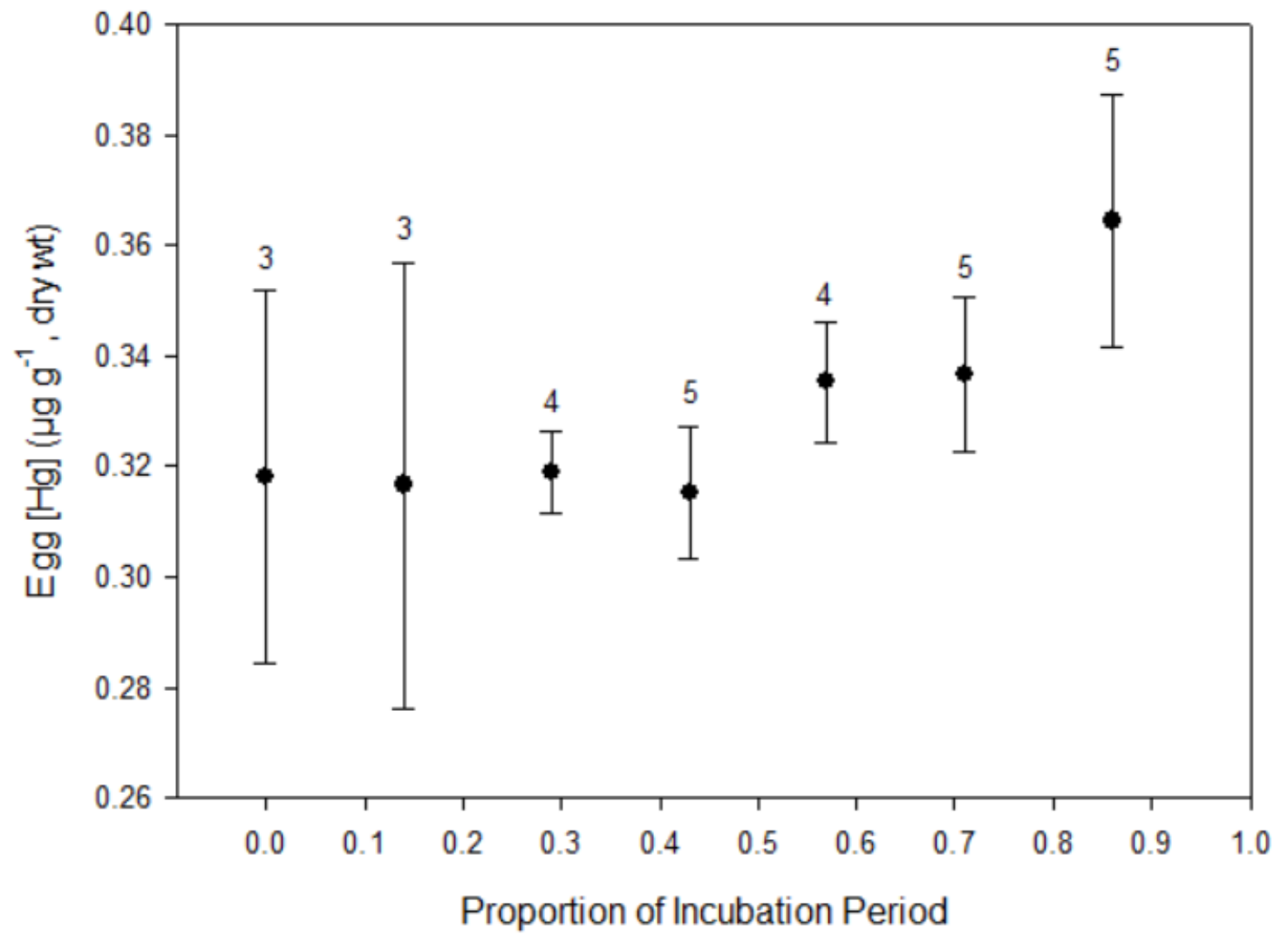

Figure 2.1 Mean ( \pm 1 STD) dry weight mercury concentration in chicken eggs dosed with MeHg at day 0. Eggs were sampled throughout incubation. Stage of incubation is expressed as a proportion of the 21-day incubation period. Sample sizes are indicated above each point. Egg Hg concentrations were statistically greater in late stage incubated eggs ( $86 \%$ of total incubation period) compared to eggs at $43 \%$ incubation. 


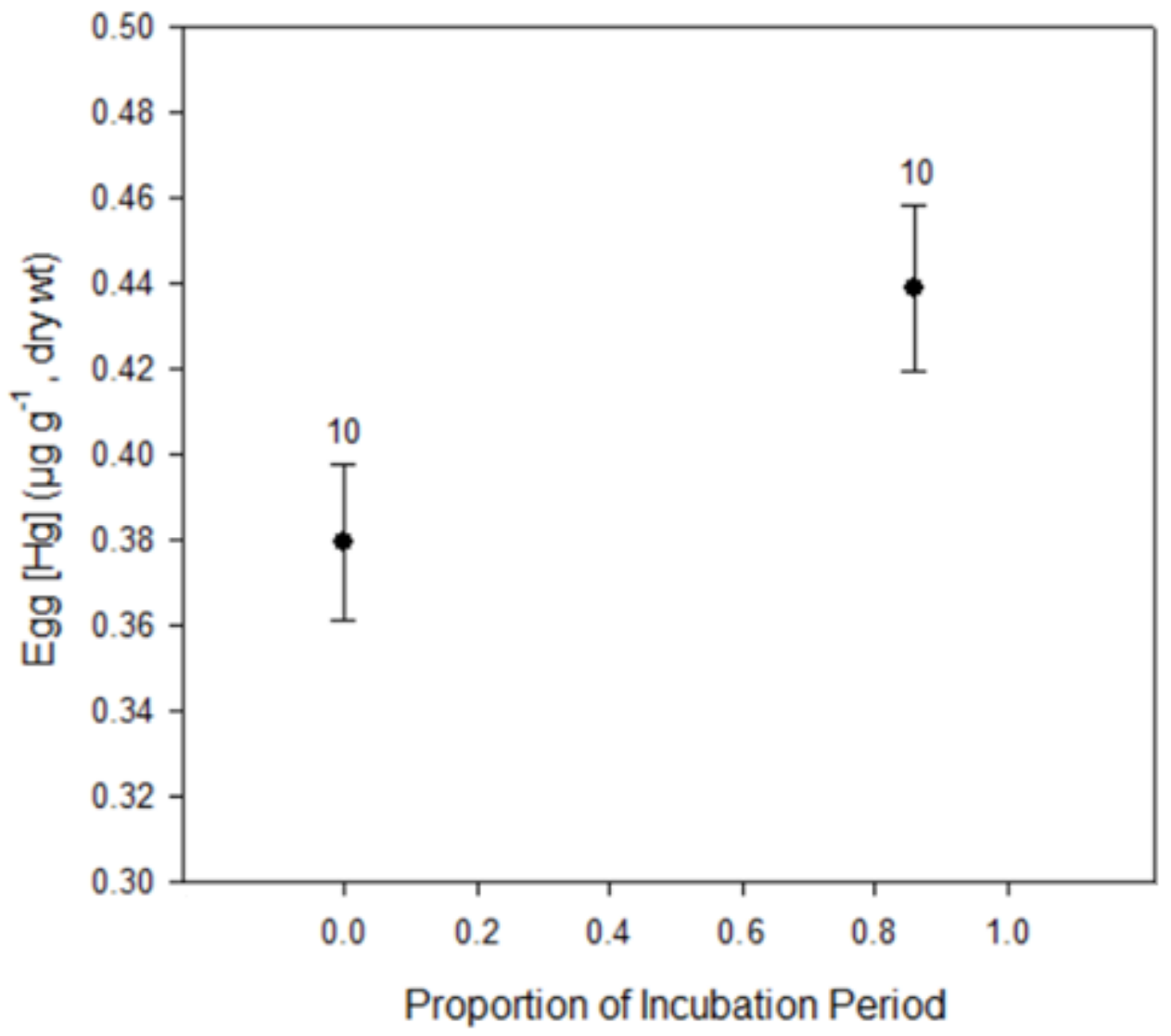

Figure 2.2 Mean ( \pm 1 STD) dry weight mercury concentration in chicken eggs dosed with MeHg at day 0. Eggs were sampled at the beginning and end of incubation. Eggs at late stage of total incubation period had significantly higher concentrations of mercury than eggs at early stage of total incubation period, representing a $14.5 \%$ increase. Sample sizes are indicated above the means. 


\section{Incubation Adjustment Factor}

Using gull eggs collected in 2014 and 2015, a significant relationship was observed between stage of incubation and the incubation adjustment factor calculated from egg contents mass and egg volume $\left(r^{2}=0.67, P<0.001, n=212\right.$; Figure 2.3). As eggs progressed through embryonic development, the incubation adjustment factor decreased, reflecting mass lost throughout incubation. This result validated the use of the adjustment factor for adjusting $\mathrm{Hg}$ concentrations in chicken eggs sampled at the beginning and end of incubation. Mean adjusted egg $\mathrm{Hg}$ concentrations were not statistically different between early stage and late stage egg incubation (2-tailed t-test, $t=2.04, d f=18, P=0.06$;

Figure 2.4). The mean difference in adjusted egg $\mathrm{Hg}$ concentrations between early and late stages of total incubation periods was $5.1 \%$, a reduction from $14.5 \%$ for unadjusted dry weight egg Hg concentrations. 


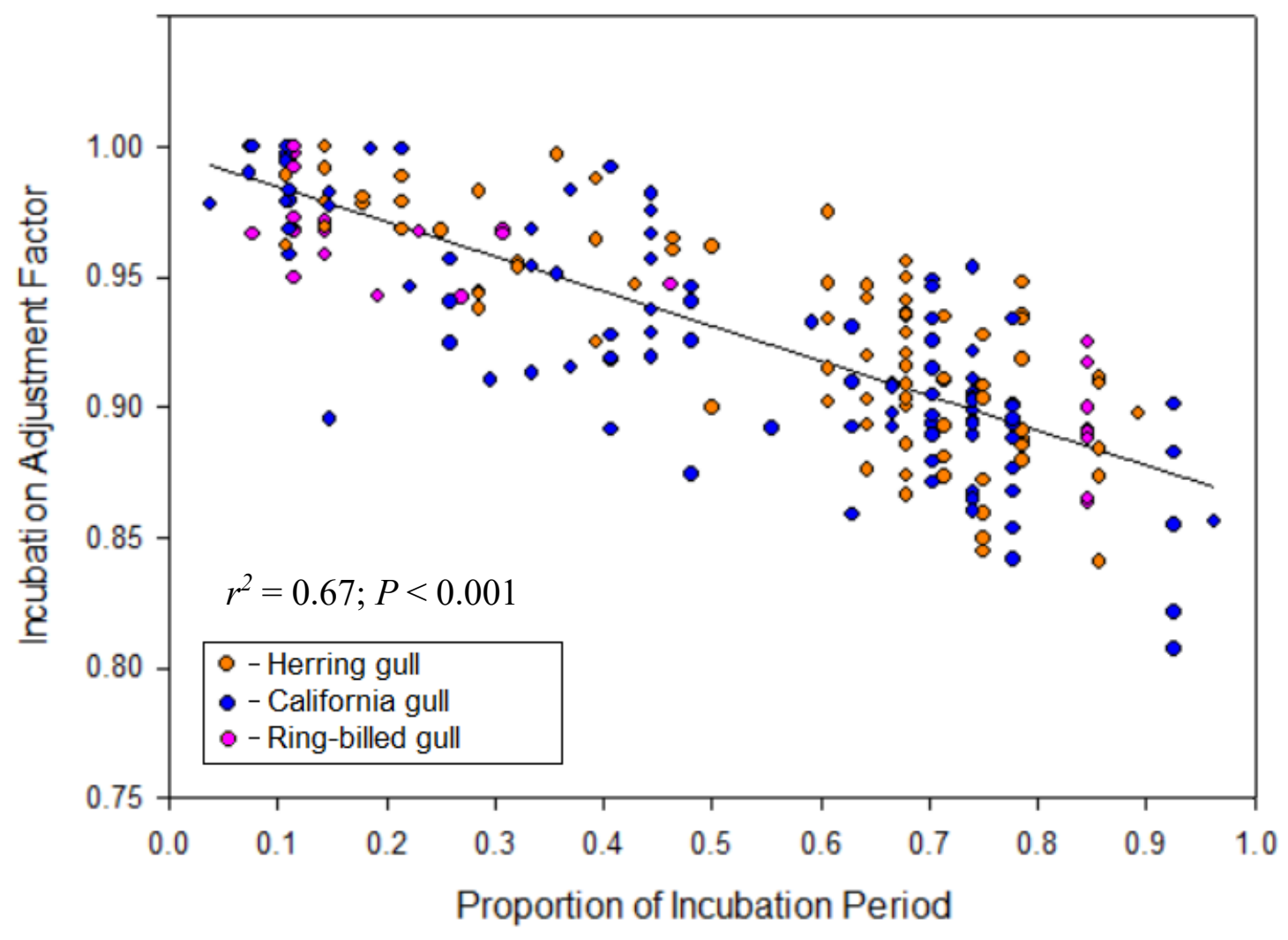

Figure 2.3 Relationship between the proportion of the incubation period completed when gull eggs were collected and the incubation adjustment factor. 


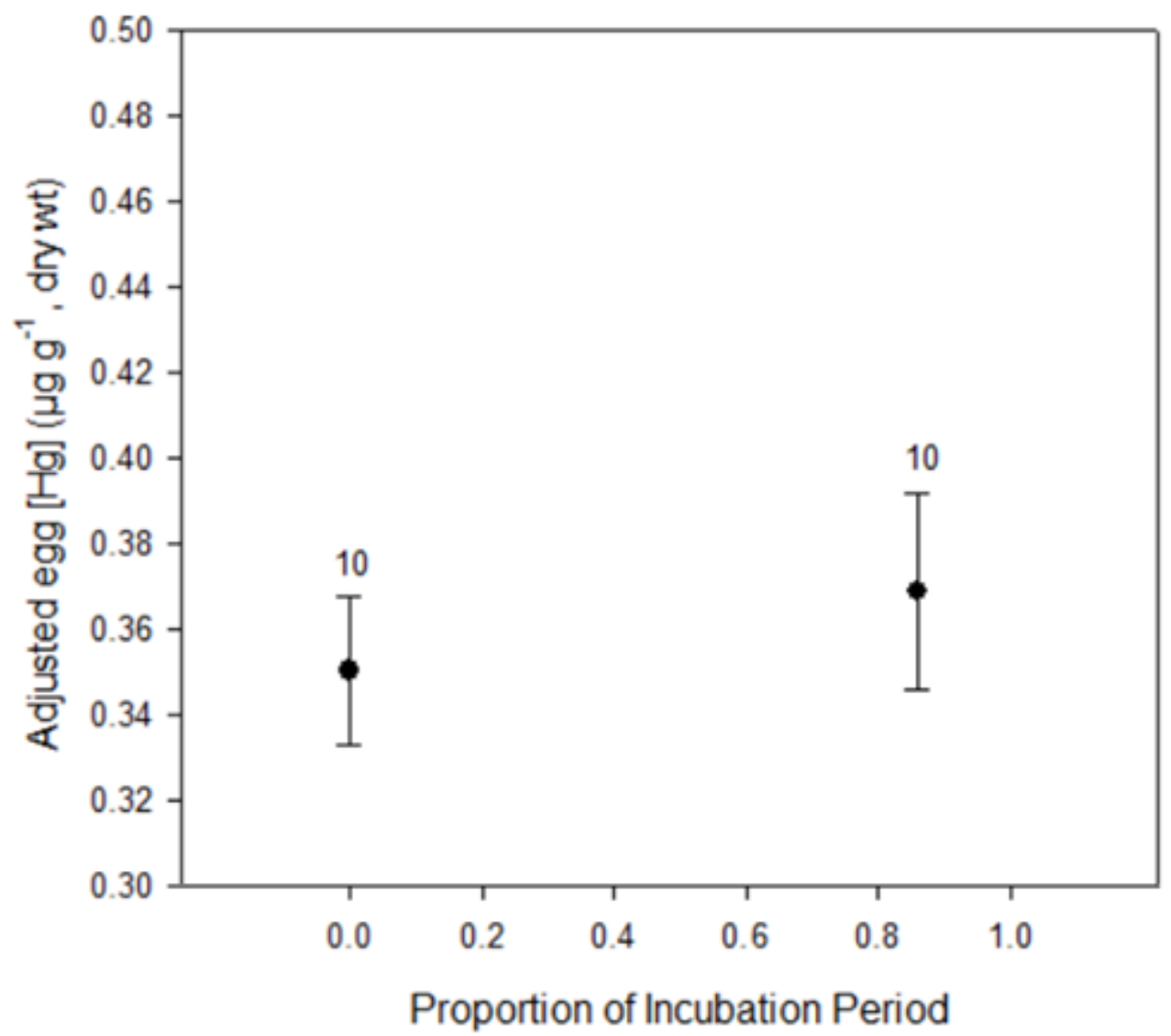

Figure 2.4 Mean adjusted ( \pm 1 STD) dry weight mercury concentration in chicken eggs dosed with MeHg at day 0. Eggs were sampled at the beginning and end of incubation. Levels of mercury adjusted for stage of development were not statistically different in eggs at early or late stages of total incubation period. Sample sizes are indicated above the means. 


\section{Discussion}

\section{Gull Eggs as Local Indicators}

Foraging ecology is linked to specific isotopic signatures in bird tissues. These isotopic signatures provide a method for estimating diet in waterbirds. Sulfur isotopes in tissues of birds can be used to discriminate between freshwater and marine prey sources used for nutrient allocation to reproduction. $\delta^{34} \mathrm{~S}$ values in marine foragers are expected to be higher than those foraging in inland environments, either on terrestrial or freshwater food sources. Lott et al. proposed a threshold $\delta^{34} \mathrm{~S}$ value of $10 \%$ for marine foragers; inland foragers should have $\delta^{34} \mathrm{~S}$ values less than $10 \%$ (Lott et al. 2003). In a study by Hobson et al. (1997), three components of egg (yolk lipids, yolk proteins, eggshell carbonates) were examined in Caspian Terns (Sterna caspia) and Double-Crested Cormorants (Phalacrocorax auritus), two migrant species breeding on Lake Ontario. Based on both carbon and sulfur isotopic signatures, all egg components reflected local freshwater food webs. Although it was possible that eggs of these migrant species incorporated isotopic signals from freshwater stopover habitats, isotope values in their eggs were comparable with those of species that were year-round residents of Lake Ontario. $\delta^{34} \mathrm{~S}$ values in gull eggs from my study fell within the expected range for freshwaters, suggesting that resources used for egg formation likely originated from inland breeding grounds. As expected income breeders, gulls are likely allocating freshwater resources obtained at or near their breeding colonies to egg production. Gulls typically arrive at their breeding colonies at least a month prior to egg laying and feed within an approximate 40 $\mathrm{km}$ radius, and so are unlikely to be incorporating isotopic signatures from overwintering areas or freshwater stopover habitats into their eggs. 
The highest $\delta^{34} \mathrm{~S}$ values were found in Herring Gull eggs from Great Slave Lake likely reflecting the unique sulfate mineral geology in the area (Carr et al. 2017). The range in sulfur isotopic signatures in the egg samples presented here can likely be explained by producers utilizing different sources of sulfur, even within a biome. For example, depending on the water source for plants at the base of the food web, rainwater and pore water ranges of $\delta^{34} \mathrm{~S}$ can vary significantly; isotopic range of values is most likely a function of sources and organic loads of sulfur rather than metabolic effects of organisms (Connolly et al. 2004).

Information regarding food web interactions, e.g. trophic position, can be gained through the use of stable nitrogen and carbon isotopes. However, their utility in identifying habitat use is confounded by trophic fractionation, e.g. nitrogen, and intra-biome variation in isotope values, e.g. carbon (Hesslein et al. 1991; Fry et al. 1999). Hence, measuring isotopes of additional elements, e.g. sulfur, may be more informative for determining nutrient sources in bird eggs.

Sulfur signatures found in gull eggs in my study were all within the proposed range for inland foraging sources. These results provide support for the use of gull eggs as indicators of environmental conditions around breeding colonies.

\section{Stage of Development and Incubation Adjustment Factor}

For $\mathrm{Hg}$ monitoring programs using eggs of colonial waterbirds, logistical constraints often lead to eggs being collected at different time points, resulting in samples being utilized that vary in their stage of development. This could have serious implications 
when expressing $\mathrm{Hg}$ concentrations on a dry weight basis since dry mass of egg contents does not remain constant as development of the embryo progresses.

Injecting freshly laid chicken eggs with a known, equal dose of $\mathrm{MeHg}$ resulted in significantly different $\mathrm{Hg}$ concentrations throughout incubation, with a $14.5 \%$ increase in egg concentrations between the beginning and near the end of the incubation period. This result was not completely unexpected, based upon what is known regarding the physiology of growing avian embryos. A freshly laid egg is composed of a specific water to dry weight fraction. As incubation and embryonic development progress, dry matter is catabolized, resulting in metabolic water production and potentially increasing the water fraction of the egg. Hence, for optimal hatching success, water must diffuse through the porous shell membrane which is controlled by internal water vapour pressure in the egg, speciesspecific eggshell physiology, nest micro-climate and parental incubation behaviour (Rahn 1984). Mortality in incubated eggs has been demonstrated for both high degrees of dehydration (Meir and Ar 1987) and water oversaturation (Romanoff 1930). For chicken eggs, overhydration of the yolk, albumen and inner eggshell membranes affected regulation of embryonic nourishment and metabolic processes of the egg, as well as hindering pipping and respiration (Romanoff 1930). Therefore, for successful hatching, the optimal dry weight to water fraction needs to be maintained throughout incubation. Metabolic water diffusing out of the egg can be considered as a fraction of solids consumed by the embryo, decreasing the egg's dry mass through time. This is particularly important after midincubation, when embryonic metabolism greatly increases (Vleck et al. 1980).

When expressing Hg concentrations in eggs on a dry weight basis, concentration values may be biased high for samples analyzed at later stages of development. A chicken 
egg hatches at day 21, making the point of mid-incubation around day 10/11. Based on Figure 2.1, we see a trend through time towards increasing $\mathrm{Hg}$ concentrations through incubation. There is an indication, however, that the relationship between stage of development and $\mathrm{Hg}$ concentration in eggs is not linear but may track changes in embryonic metabolic rate which increases exponentially after mid-incubation (Vleck et al. 1980). In the context of evaluating egg $\mathrm{Hg}$ levels, this requires further investigation involving more injection experiments with larger sample sizes and more time points to confirm this hypothesis.

Changes in egg dry weight $\mathrm{Hg}$ concentrations associated with incubation were largely eliminated through the application of the incubation adjustment factor, decreasing the $14.5 \% \mathrm{Hg}$ concentration difference to $5.1 \%$ between initial and final stages of incubation. Based on my results, the application of the adjustment factor is likely most important for eggs at post mid-incubation stages of development. As noted above, embryonic metabolic rate increases greatly during these later stages, a pattern that has been reported for a wide variety of altricial and precocial bird species (Vleck et al. 1980).

Interpretation of $\mathrm{Hg}$ concentrations in biotic samples across multiple sites is confounded by a variety of factors. It becomes important to remove variability to standardize samples for more meaningful spatial comparisons. Hg concentrations based on dry weight have been shown to increase significantly at later stages of incubation, and this phenomenon can largely be accounted for through an incubation adjustment factor based on egg morphological parameters. This approach could be routinely applied in $\mathrm{Hg}$ studies using eggs as a matrix for biomonitoring studies. 


\title{
CHAPTER THREE
}

\author{
APPLICATION OF \\ AMINO ACID-COMPOUND SPECIFIC \\ NITROGEN ISOTOPE ANALYSIS \\ FOR ASSESSING SPATIAL TRENDS IN MERCURY
}




\section{Introduction}

Assessing spatial and temporal changes in levels of environmental contaminants is a primary objective of chemical monitoring programs. This information is critical for identifying sources of contaminants and emerging contaminants of concern, and for implementing strategies to reduce releases of contaminants into the environment. Many contaminant monitoring programs are based on interpretation of data collected through the analysis of wildlife samples (Weseloh et al. 2011; Burgess et al. 2013; Braune et al. 2015; Elliott and Elliott 2016). Biomagnifying contaminants reach their highest levels in top predators, thereby facilitating measurement of chemicals that are present at low levels in abiotic matrices. However, a complication associated with the use of biota as contaminant monitors stems from the degree to which their diets may vary intra- and inter-specifically, and across space and time (Hebert et al. 1999, 2000, 2008). Diet is a critical factor regulating exposure to, and uptake of, biomagnifying contaminants. Therefore, it is necessary to consider how diet may influence the interpretation of contaminant trends in biomonitoring organisms (Hebert and Weseloh 2006). Typically, this is addressed through the measurement of stable nitrogen isotopes $\left({ }^{15} \mathrm{~N} /{ }^{14} \mathrm{~N}\right.$ relative to a standard expressed as $\delta^{15} \mathrm{~N}$ values). In general, $\delta^{15} \mathrm{~N}$ values increase with increasing trophic position, so higher $\delta^{15} \mathrm{~N}$ values should reflect increased exposure and uptake of biomagnifying contaminants (Hebert et al. 2000). However, the interpretation of $\delta^{15} \mathrm{~N}$ values in this manner may only be appropriate when comparing individuals or species at one location during the same time period (Post 2002). When comparing $\delta^{15} \mathrm{~N}$ values in organisms over space or time, even at one site, it is necessary to investigate possible differences in $\delta^{15} \mathrm{~N}$ values associated with nitrogen being incorporated into the base of the food web, as different sources may have 
different $\delta^{15} \mathrm{~N}$ values. This is often accomplished by measuring $\delta^{15} \mathrm{~N}$ values in primary invertebrate consumers, such as filter-feeding molluscs. Primary consumer $\delta^{15} \mathrm{~N}$ values are used as a baseline from which trophic position estimates can be generated for higher order consumers (Cabana and Rasmussen 1994). However, studies evaluating spatial and temporal differences in contaminant levels are often based upon the use of samples for which no such food web samples exist, e.g. archived samples from environmental specimen banks. In this situation, it is necessary to develop another means to assess baseline $\delta^{15} \mathrm{~N}$ values.

Amino acid-compound specific stable nitrogen isotope analysis (AA-CSIA) generates both baseline and trophic position $\delta^{15} \mathrm{~N}$ values from the same sample. Individual amino acids (AA) differ in their $\delta^{15} \mathrm{~N}$ values and most AA can be categorized as either "source" or "trophic" (Popp et al. 2007). $\delta^{15} \mathrm{~N}$ values of source AA retain the baseline/source $\delta^{15} \mathrm{~N}$ values associated with the diet of higher order consumers (Popp et al. 2007) reflecting the fact that the dominant metabolic pathways for these AA do not involve transamination reactions. Trophic AA, in contrast, undergo extensive deamination and transamination reactions resulting in trophic discrimination of nitrogen isotopes and higher $\delta^{15} \mathrm{~N}$ values in these AA in consumers versus their diets (Chikaraishi et al. 2007; McMahon and McCarthy 2016). Most studies applying the AA-CSIA approach to estimate organism trophic position have focused on using phenylalanine (Phe) and glutamic acid (Glu) as source and trophic AA respectively (McClelland and Montoya 2002; Popp et al. 2007). Studies involving diverse taxa, including birds, have shown their utility in this context (McClelland and Montoya 2002; Chikaraishi et al. 2007, 2009; McCarthy et al. 2007; Lorrain et al. 2009; Bradley et al. 2015; McMahon et al. 2015; Nielsen et al. 2015; Hebert 
et al. 2016). Various formulas for estimating trophic position have been suggested, but estimating trophic position across entire food chains is complicated by ecosystem-specific differences in nitrogen isotope fractionation in primary producers (Chikaraishi et al. 2014) and because of differences in trophic discrimination factors between Glu and Phe across taxa (Germain et al. 2013; Hoen et al. 2014). To avoid the complexities associated with trying to define absolute trophic position across entire food chains, it may be simpler, within a taxon, to use the difference between $\delta^{15} \mathrm{~N}$ values in Glu and Phe $\left(\delta^{15} \mathrm{~N}_{G l u P h e}\right)$ as a proxy for "relative" trophic position.

A major drawback of the AA-CSIA approach is that it is costly and laborious, limiting the numbers of samples that can be analysed. For contaminant studies, it is currently not practical to conduct AA-CSIA on individual samples. One possible way to circumvent this issue is by generating site specific baseline nitrogen isotope values $\left(\delta^{15} \mathrm{~N}\right.$ in Phe) from AA-CSIA of sample pools (pools are made up of samples from individuals with each individual contributing the same sample mass to the pool) and then applying those baselines to bulk $\delta^{15} \mathrm{~N}$ values measured in the individual samples constituting those pools. As a first step in assessing the feasibility of such an approach in birds, I investigated the degree to which $\delta^{15} \mathrm{~N}_{\text {BulkPhe }}$ values are related to $\delta^{15} \mathrm{~N}_{\text {GluPhe }}$ values in gull egg pools collected from 25 locations across Canada. I then focused on the application of $\delta^{15} \mathrm{~N}_{\text {BulkPhe }}$ values to interpret spatial patterns in mercury levels in individual gull eggs collected along a north-south gradient in western Canada. There is some evidence that $\mathrm{Hg}$ levels in highlatitude biota, including waterbirds, may be increasing through time (Braune 2007; Braune et al. 2015), that biomagnification of $\mathrm{Hg}$ may be greater in northern regions (Lavoie et al. 2013), and that industrial activity may be influencing Hg bioavailability in parts of northern 
Alberta (Kelly et al. 2010). For these reasons, I assessed the strength of latitudinal gradients in $\mathrm{Hg}$ concentrations in gull eggs over a relatively large area which included sites in the oil sands region of northern Alberta, Canada. To assess spatial patterns of Hg levels in western Canada, eggs of various gull species were collected from 12 sites across a 14 degree latitudinal gradient (Figure 1.1).

\section{Latitudinal Effects On Mercury Biomagnification}

Evidence suggests that $\mathrm{Hg}$ biomagnification may be greater in northern regions, based on a worldwide meta-analysis (Lavoie et al. 2013). Lavoie et al. (2013) cite various temperature-linked possibilities for the trend, including suppressed growth and decreased excretion rates of aquatic organisms in colder temperatures, resulting in increased bioaccumulation of $\mathrm{Hg}$ in tissues. Furthermore, simpler food webs at higher latitudes limits choice of prey for consumers at higher trophic levels possibly increasing the efficiency of Hg transfer along a given food chain (Lavoie et al. 2013).

No data on $\mathrm{Hg}$ trends in colonial waterbird eggs along a latitudinal gradient exist for the northern Alberta region. My study offers a unique perspective on trends of concentrations of $\mathrm{Hg}$ in wildlife in this area. Here, I test the hypothesis that $\mathrm{Hg}$ concentrations in colonial waterbird eggs increase with latitude. Since the egg samples varied in their stage of development, I used an adjustment factor to correct for this (see

\section{Chapter 2).}




\section{Mercury Sources and Processes Regulating MeHg Production}

Mercury emissions from anthropogenic sources have an important atmospheric component such that emission sources and regions of deposition may be thousands of kilometers apart (Jaffe and Strode 2008). Hg deposition in the Canadian Arctic has been linked to Asian sources (NCP 2012). Such long-range transport may be driving spatial contaminant trends in my study region; if long-range deposition is indeed the primary source of $\mathrm{Hg}$, I expect a uniform distribution of $\mathrm{Hg}$ in this relatively small geographic area.

Some sampling sites in my study are located along the Athabasca River and the Peace-Athabasca Delta (PAD), which correspond to bodies of water potentially affected by industrial development in the region, e.g. the Athabasca Oil Sands. Recent research provides conflicting views regarding the impact of oil sands development on $\mathrm{Hg}$ availability in the region (Kelly et al. 2010; Wiklund et al. 2012; Kirk et al. 2014). My study contributes additional biotic monitoring data. If oil sands development is important in affecting $\mathrm{Hg}$ inputs into the Athabasca River, my a priori expectation is to see higher Hg levels in eggs collected from sites in receiving waters of the Athabasca River.

As described in Chapter 1, the hydrological complexity and sediment deposition of the Peace-Athabasca Delta is influenced by two major rivers. Both rivers are important sources of water and sediment to the Delta and may, therefore, be regulating contaminant transport to the Delta. However, contamination of aquatic systems by $\mathrm{Hg}$ is inherently complex and likely impacted by multiple factors. Though the rate of supply of elemental $\mathrm{Hg}$ to ecosystems may be regulating local levels, evidence suggests that methylation rates may be more important than inorganic $\mathrm{Hg}$ loading when determining fish $\mathrm{MeHg}$ exposure (Eagles-Smith et al. 2016). Physio-chemical parameters of lakes also play a major role in 
regulating $\mathrm{Hg}$ bioavailability; $\mathrm{pH}$ and dissolved organic carbon (DOC) levels appear to influence $\mathrm{Hg}$ dynamics at the base of aquatic food chains (Chen et al. 2005; Driscoll et al. 2007). To investigate possible water chemistry influences on egg $\mathrm{Hg}$ levels, I examine data regarding waterbody $\mathrm{pH}$ and dissolved organic carbon (DOC).

\section{Methods}

Assessing the Relationship Between $\delta^{15} N_{\text {GluPhe }}$ and $\delta^{15} N_{\text {BulkPhe }}$ values

Eggs from four gull species: Herring Gull (Larus argentatus smithsonianus), California Gull (L. californicus), Glaucous-Winged Gull (L. glaucescens), and Ring-Billed Gull (L. delawarensis) were collected in various years from 25 locations situated across Canada including the 12 sites shown in Figure 1.1. At each location, species-specific egg pools were created that consisted of 5-15 eggs combined on an equal weight basis. In total, 69 egg pools were analyzed by AA-CSIA at the University of Hawaii's Biogeochemical Stable Isotope Facility according to established methods (Popp et al. 2007; Hannides et al. 2009). The following approach generated amino acid-specific $\delta^{15} \mathrm{~N}$ values for a variety of AA, including Glu and Phe. First, amino acids were chemically isolated and purified from egg homogenate samples. Dried, ground tissue $(10 \mathrm{mg})$ was hydrolyzed $(6 \mathrm{~N} \mathrm{HCl})$ at 150 ${ }^{\circ} \mathrm{C}$ for $70 \mathrm{~min}$. Acid hydrolysis under these conditions cleaves the terminal amide groups in glutamine (Gln), resulting in the conversion of this AA to Glu. Thus, the isotope value of a combined Glu + Gln is measured (termed Glu here). Acid hydrolysis results in the destruction of amino acids tryptophan and cystine. Hydrolysates were dissolved in $0.01 \mathrm{~N}$ $\mathrm{HCl}$ and then passed through a $0.2 \mathrm{um}$ polyether sulfone membrane (VWR), followed by cation-exchange chromatography using a vacuum manifold with commercial cartridges 
(GracePure SPE Cation-X). Samples then underwent derivatization, i.e. esterification, by heating at $110{ }^{\circ} \mathrm{C}$ for $60 \mathrm{~min}$ in 4:1 isopropanol-acetyl chloride, after which AA were acylated by heating at $100{ }^{\circ} \mathrm{C}$ for $15 \mathrm{~min}$ in $3: 1$ methylene chloride-trifluoracetic anhydride (TFAA). Using a 2:1 P-buffer-chloroform mix (1 M P-buffer: $\mathrm{KH}_{2} \mathrm{PO}_{41} \mathrm{Na}_{2} \mathrm{HPO}_{4}$ in Milli$\mathrm{Q}$ water, $\mathrm{pH}$ 7), AA were further purified by partitioning into chloroform, discarding any compounds dissolved in the aqueous phase. A final acylation step was repeated, and samples were stored in $3: 1$ methylene chloride-TFAA at $-20^{\circ} \mathrm{C}$. Samples were dried under $\mathrm{N}_{2}$ at ambient temperature and dissolved in ethyl acetate just prior to isotope analysis. $\delta^{15} \mathrm{~N}$ values (\%o, relative to atmospheric $\mathrm{N}_{2}$ ) of derivatized samples were determined using an isotope ratio mass spectrometer (either a Thermo Scientific Delta V Plus or a Thermo Scientific MAT 253) interfaced to a trace GC gas chromatograph (Thermo Finnigan) via a GC-C III combustion interface (Thermo Finnigan $980{ }^{\circ} \mathrm{C}$ ). Samples were injected (split-splitless injector in splitless mode) onto a forte $\mathrm{BP} \times 5$ capillary column $(60 \mathrm{~m} \times 0.32$ $\mathrm{mm} \times 1.0 \mu \mathrm{m}$ film thickness) at an injector temperature of $180^{\circ} \mathrm{C}$ with a constant helium flow rate of $1.4 \mathrm{~mL} / \mathrm{min}$. The column was initially held at $50{ }^{\circ} \mathrm{C}$ for 2 min and then increased to $120^{\circ} \mathrm{C}$ at a rate of $15^{\circ} \mathrm{C} / \mathrm{min}$. Once at $120^{\circ} \mathrm{C}$, the temperature was increased at a rate of $4{ }^{\circ} \mathrm{C} / \mathrm{min}$ to $195^{\circ} \mathrm{C}$, increased by $5{ }^{\circ} \mathrm{C} / \mathrm{min}$ to $255^{\circ} \mathrm{C}$, and then increased by 15 ${ }^{\circ} \mathrm{C} / \mathrm{min}$ to $300{ }^{\circ} \mathrm{C}$, where it was held for $8 \mathrm{~min}$. All samples were analyzed at least in triplicate. Between triplicate runs of each sample, a suite of AA (alanine, threonine, isoleucine, proline, Glu, and Phe) of known isotopic composition were analyzed. In addition, internal reference compounds, norleucine and aminoadipic acid, were coinjected with these AA and all samples. For isotopic correction of unknown AA when co-injected standards were unusable due to co-elution effects, a linear correction was derived from the 
AA suites run immediately before and after the triplicate sample analysis and applied to measured isotope ratios. The standard deviation of $\delta^{15} \mathrm{~N}$ values derived from replicate analyses averaged $0.52 \%$ and ranged from $0.03 \%$ to $1.2 \%$.

Standard bulk stable nitrogen isotope analysis was also conducted on the egg pools. Freeze-dried egg tissue was encapsulated in tin $(1.0 \pm 0.1 \mathrm{mg})$ and analyses were completed at the University of Ottawa's G.G. Hatch Stable Isotope Laboratory. The analysis was conducted with a CE 1110 Elemental Analyser followed by continuous flow analysis using a DeltaPlus Advantage isotope ratio mass spectrometer (Thermo Scientific) coupled with a ConFlo III. International standards were used for calibration, and quality control involved use of sample duplicates.

Linear regression analysis was used to examine the relationship between $\delta^{15} \mathrm{~N}_{\text {GluPhe }}$ and $\delta^{15} \mathrm{~N}_{\text {BulkPhe }}$ values using Statistica Ver. 12 (StatSoft 2013).

\section{Assessment of Spatial Trends in THg in Gull Eggs from Western Canada}

Total mercury (THg) analysis was conducted on individual gull eggs collected from 12 locations in 2014 and 2015. Sites were located on a north-south gradient over 14 degrees of latitude (Figure 1.1). Species included were California Gull, Herring Gull, and Ring-Billed Gull. At most sites, between 10 and 15 eggs were collected and analysed from each site in each year. However, at two sites (Daring Lake and Egg Island, Lake Athabasca) fewer Herring Gull eggs were collected annually (3-5) because of small nesting populations. In total, 431 eggs were collected and analyzed from the 12 sites in 2014 and 2015 (Table 1.1). 
All collected eggs were numbered and stored in foam-lined Pelican cases and transported to Environment and Climate Change Canada's National Wildlife Research Centre (NWRC; Ottawa, Canada). Prior to opening, maximum egg length and breadth were measured. Whole eggs were opened in biosafety cabinets and egg contents mass recorded. Egg contents (yolk and albumen) were homogenized together using an electric mixer and chemically clean techniques. Samples showing signs of embryonic development were homogenized with a cryogenic ball-mill to ensure complete pulverization of embryonic components. Homogenates were aliquoted into acid-washed glass and polypropylene containers. Sub-samples of equal weight from same site and same species were used to create pooled samples. All samples were stored at $-40^{\circ} \mathrm{C}$ prior to chemical analysis.

In eggs, approximately 96\% of THg is methyl $\mathrm{Hg}$ (MeHg) (Ackerman et al. 2013) so measuring $\mathrm{THg}$ is an efficient, cost-effective way to assess $\mathrm{MeHg}$ levels in eggs. Homogenates stored in polypropylene vials were freeze-dried for at least $48 \mathrm{hrs}$ using a Labconco FreezeZone 6 Litre Freeze Dry System (Model 77530), wet and dry weights were recorded and moisture content calculated. Approximately $20 \mathrm{mg}$ of dried egg contents were aliquotted onto nickel boats and delivered by autosampler to the furnace of an Advanced Mercury Analyzer (AMA-253, Altec, Czech Republic) for chemical and thermal decomposition. Following decomposition, the resulting vapor was carried by ultrapure oxygen to an amalgamator which selectively trapped $\mathrm{Hg}$. Total collected $\mathrm{Hg}$ was released to the atomic absorption spectrometer for detection measured at $253.65 \mathrm{~nm}$. Quality assurance methods involved the use of certified reference material (OT1566b, TORT(3), DOLT(4), IAEA-407, BCR-463) and sample duplicates. THg concentrations 
measured in all the samples were within the concentration ranges of certified reference materials. Limit of detection for THg was $0.006 \mu \mathrm{g} \cdot \mathrm{g}^{-1}$ (dry weight).

A species-specific pooled egg sample, collected in 2014 from each of the 12 sites, underwent AA-CSIA to generate site-specific $\delta^{15} \mathrm{~N}$ baselines ( $\delta^{15} \mathrm{~N}$ in Phe) using the same techniques outlined above. These baseline values were applied to the bulk isotope values measured in individual eggs collected in 2014 and 2015. This normalization of individual egg bulk $\delta^{15} \mathrm{~N}$ values generated egg $\delta^{15} \mathrm{~N}$ values ( $\delta^{15} \mathrm{~N}_{\text {BulkPhe }}$ ) that were comparable across species and sites. This approach assumed that the isotopic baseline at each site did not change between 2014 and 2015 .

\section{Water Chemistry - Dissolved Organic Carbon and $p H$}

Water samples were collected in 2015 from 6 sites (Lac La Biche, Namur Lake, Rocky Island Lake, Bistcho Lake, Lake Athabasca, Great Slave Lake) using a $60 \mathrm{~mL}$ disposable plastic syringe fitted with a polyethersulfone disk filter ( $32 \mathrm{~mm}$ diameter, 0.45 $\mu \mathrm{m}$ membrane pore size). Water was collected from lake surfaces from shores near nesting colonies. Approximately $50 \mathrm{~mL}$ of sample from each site was filtered into individual amber glass jars and stored at $4^{\circ} \mathrm{C}$. Dissolved organic carbon samples were analyzed at RPC Laboratories (Fredericton, NB) using ultraviolet-persulfate digestion followed by nondispersive infrared sensor detection. $\mathrm{pH}$ was measured by immersing a calibrated YSI 600QS Sonde with 650 Multiparameter Display System (YSI Incorporated, Yellow Springs, Ohio) one meter under the surface of the water at the same sites. Data for water chemistry at other sites in Alberta, Saskatchewan and Northwest Territories were provided by appropriate water quality monitoring agencies. 


\section{Statistical Analysis}

Individual egg $\mathrm{THg}$ concentrations $\left(\mu \mathrm{g} \cdot \mathrm{g}^{-1}\right.$, dry wt) were corrected for stage of development using an incubation adjustment factor based on individual egg morphological parameters (egg contents mass / egg volume; Chapter 2).

For the examination of latitudinal trends, nonparametric correlations (Spearman correlations, $\mathrm{r}_{\mathrm{s}}$ ) were used to examine relationships between concentrations of $\mathrm{Hg}$ adjusted for stage of development $\left(\mu \mathrm{g} \cdot \mathrm{g}^{-1}\right.$, dry wt) in individual gull eggs, bulk $\delta^{15} \mathrm{~N}$ values (\%o), egg $\delta^{15} \mathrm{~N}_{\text {BulkPhe }}(\%)$ and sites. Linear regression was used to examine the relationship between $\log _{10}$ adjusted egg THg levels and egg $\delta^{15} \mathrm{~N}$ values (\%) normalized for baseline $\left(\delta^{15} \mathrm{~N}_{\text {BulkPhe }}\right.$. Residuals from this regression represented egg THg levels normalized for $\delta^{15} \mathrm{~N}_{\text {BulkPhe }}$ (i.e. egg $\mathrm{Hg}$ levels normalized for this proxy of trophic position, $\mathrm{Hg}_{\text {norm }}$ ). Spearman correlation was used to examine the relationship between $\mathrm{Hg}_{\text {norm }}$ and sites. Distance-weighted least squares curve-fitting (stiffness $=0.25$ ) was used to test my a priori expectation that eggs collected downstream of the oil sands could be differentiated from other locations based upon their THg levels. To investigate this further, I compared THg levels in eggs by region: north $\left(>59.2^{\circ} \mathrm{N}, 4\right.$ sites: Rocky Island Lake, Bistcho Lake, Great Slave Lake, Daring Lake), south $\left(<58^{\circ} \mathrm{N}, 5\right.$ sites: Langdon Reservoir, Miquelon Lake, Lac La Biche, Namur Lake, Preston Lake), and downstream of the Athabasca River $\left(58.9^{\circ} \mathrm{N}-\right.$ $59.2^{\circ} \mathrm{N}, 3$ sites: Mamawi Lake, Egg Island, Eastern Lake Athabasca). Kruskal-Wallis one way analysis of variance on ranks followed by Dunn's test was used to assess whether there were statistically significant inter-region differences in $\mathrm{Hg}_{\text {norm }}$. All statistical analyses were conducted using Statistica Ver. 12 (StatSoft, 2013). 


\section{Results}

Assessing the Relationship Between $\delta^{15} N_{\text {GluPhe }}$ and $\delta^{15} N_{\text {BulkPhe }}$

There was a statistically significant correlation $\left(r^{2}=0.81, P<0.001\right)$ between $\delta^{15} \mathrm{~N}_{\text {GluPhe }}$ and $\delta^{15} \mathrm{~N}_{\text {BulkPhe }}$ values in the gull egg pools analyzed from across Canada (Figure 3.1).

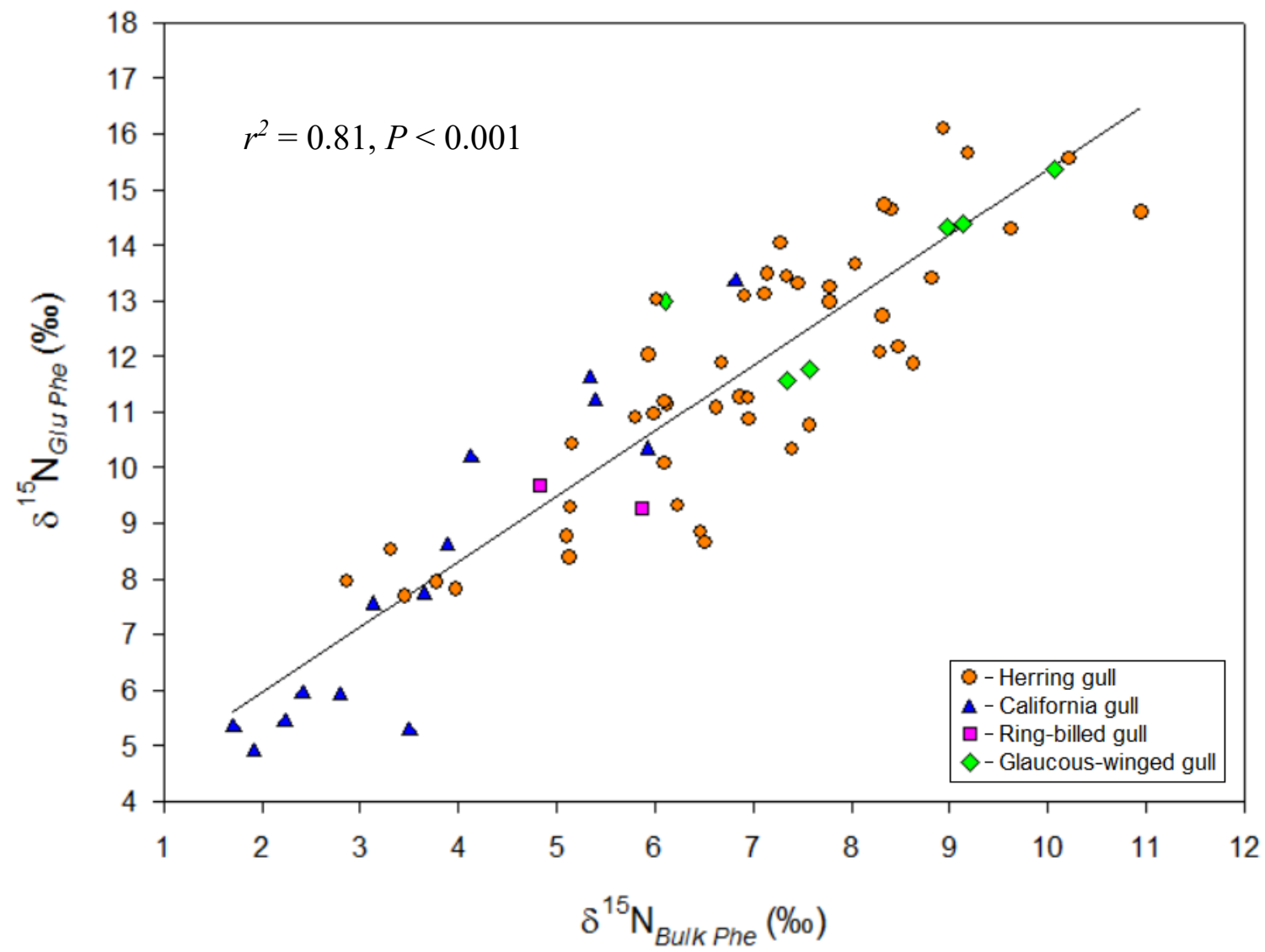

Figure 3.1 Statistically significant relationship between $\delta^{15} \mathrm{~N}_{\text {BulkPhe }}$ and $\delta^{15} \mathrm{~N}_{\text {GluPhe }}$ values in gull egg pools from 25 locations across Canada. 


\section{Assessment of Spatial Trends in THg in Gull Eggs from Western Canada}

THg concentrations in individual gull eggs were positively correlated with latitude $\left(r_{s}=0.50, P<0.001\right.$, Figure 3.2). Bulk $\delta^{15} \mathrm{~N}$ values in individual eggs were correlated with latitude but the relationship was weaker $\left(r_{s}=0.36, P<0.001\right.$, Figure 3.3). Phe $\delta^{15} \mathrm{~N}$ values in egg pools were used to estimate isotopic baseline values integrated by gulls at individual sampling locations. Bulk $\delta^{15} \mathrm{~N}$ values adjusted for isotopic baselines $\left(\delta^{15} \mathrm{~N}_{\text {Bulk- }}\right.$ Phe) showed a stronger correlation with latitude $\left(r_{s}=0.68, P<0.001\right.$, Figure 3.4). $\delta^{15} \mathrm{~N}_{B u l k-}$ Phe values were correlated with egg THg concentrations $\left(r^{2}=0.24, P<0.001\right.$, Figure 3.5). Residuals from this regression represented individual egg THg concentrations normalized for baseline-adjusted trophic position as well as stage of incubation. These residuals were weakly correlated with latitude $\left(r_{s}=0.18 ; P<0.001\right.$, Figure 3.6). However, distanceweighted least squares curve fitting (black line; stiffness $=0.25$ ) indicated that other spatial differences in egg THg levels also exist, i.e. levels at sites 6-8 (Mamawi Lake, Egg Island, Eastern Lake Athabasca) appear elevated (Figure 3.6); all of these sites were in receiving waters of the Athabasca River.

To further investigate this apparent pattern, normalized mean THg concentrations were compared across regional categories: north, south, and downstream of the Athabasca River. Normalized THg levels in eggs collected from these regions differed with those from sites in receiving waters of the Athabasca River being statistically greater than eggs collected from northern and southern regions (Kruskal-Wallis $H_{2,428}=58.7, P<0.001$; post-hoc comparisons of mean ranks, $P<0.05$, Figure 3.7). Eastern Lake Athabasca was included in the 'downstream' region despite being $\sim 150 \mathrm{~km}$ from the mouth of the PeaceAthabasca Delta. The regional egg $\mathrm{Hg}_{\text {norm }}$ concentration trends remain unchanged when 
Eastern Lake Athabasca is omitted from the 'downstream' region (Kruskal-Wallis $H_{2,367}=$ 25.5, $P<0.001$; post-hoc comparisons of mean ranks, $P<0.05)$.

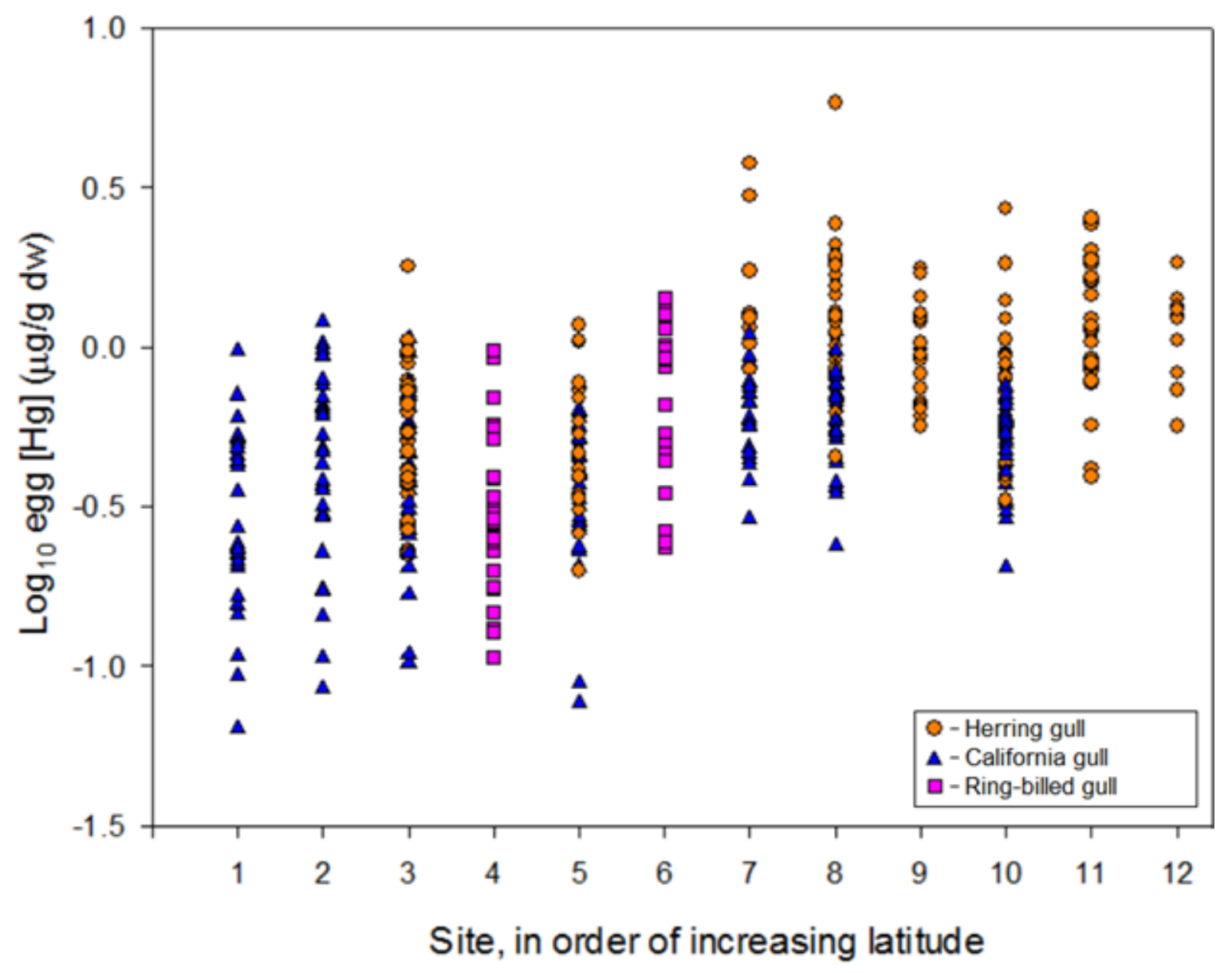

Figure 3.2 Concentrations of mercury $\left(\mu \mathrm{g} \cdot \mathrm{g}^{-1}\right.$, dry weight) in individual gull eggs increase with latitude $\left(r_{s}=0.50, P<0.001\right)$. Mercury levels are adjusted for stage of embryonic development (see text). See Figure 1.1 for corresponding site names. 


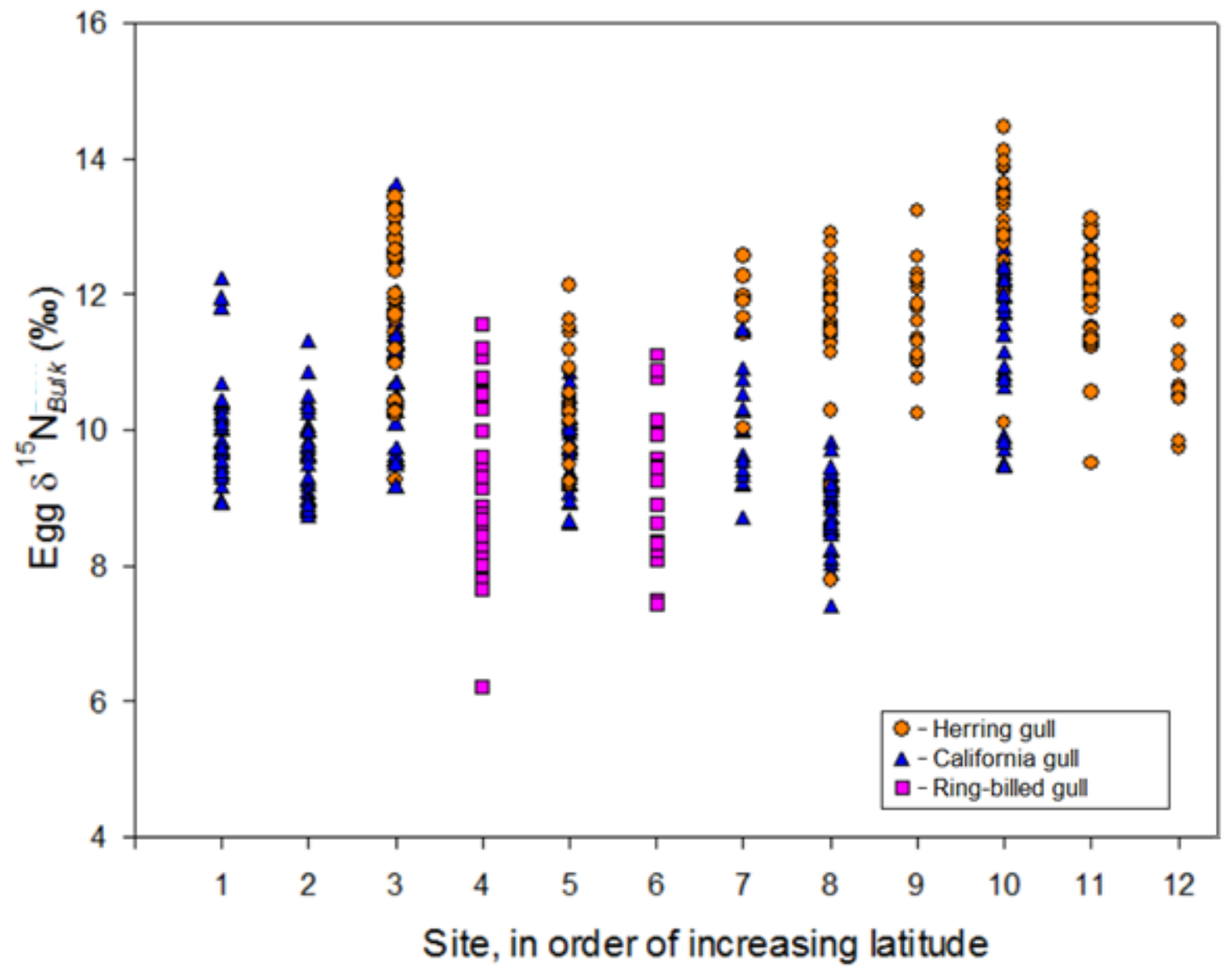

Figure 3.3 Latitude is weakly correlated with bulk $\delta^{15} \mathrm{~N}$ values (\%) in individual gull eggs $\left(r_{s}=0.36 ; P<0.001\right)$. 


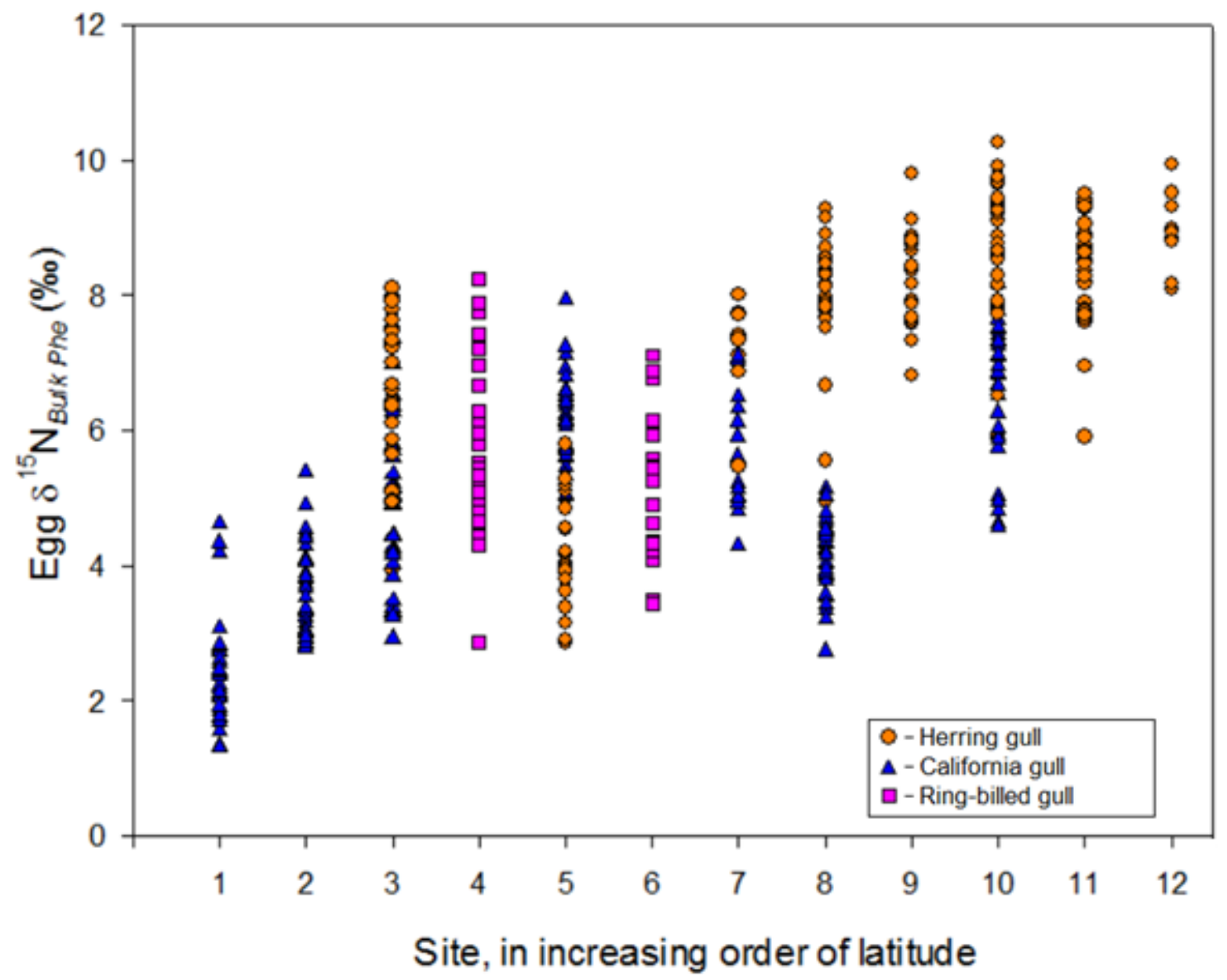

Figure 3.4 Latitude is strongly correlated with egg $\delta^{15} \mathrm{~N}$ values (\%) normalized for isotopic baselines (egg $\left.\delta^{15} \mathrm{~N}_{\text {bulk }}-\delta^{15} \mathrm{~N}_{\mathrm{Phe}}\right)\left(r_{s}=0.68, P<0.001\right)$. 


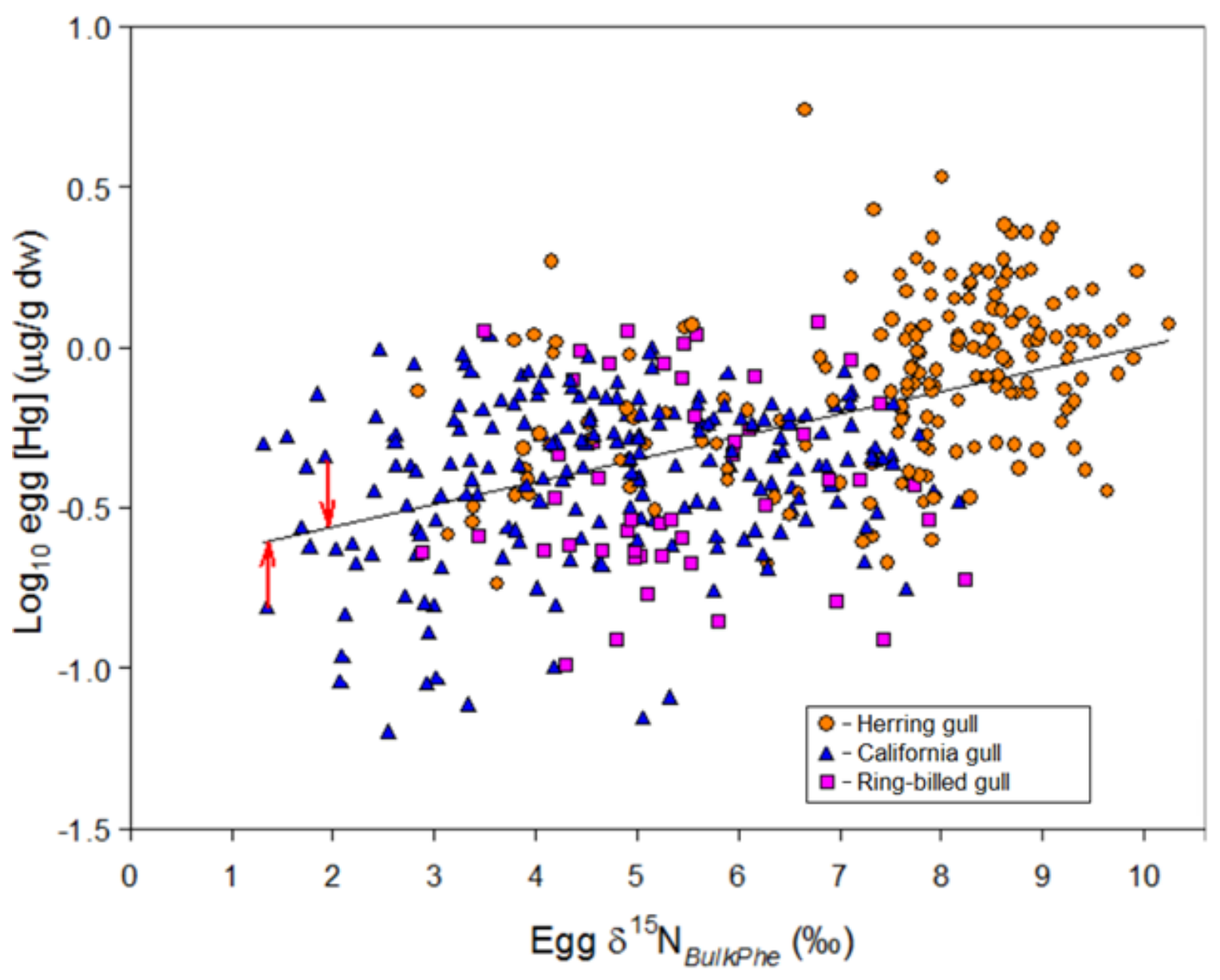

Figure 3.5 Linear regression of egg $\delta^{15} \mathrm{~N}$ values (\%) normalized for isotopic baselines versus egg THg levels $\left(r^{2}=0.24, P<0.001\right)$. Mercury levels are adjusted for stage of embryonic development (see text). Residuals (examples in red) from the regression are egg THg levels normalized for trophic position. 


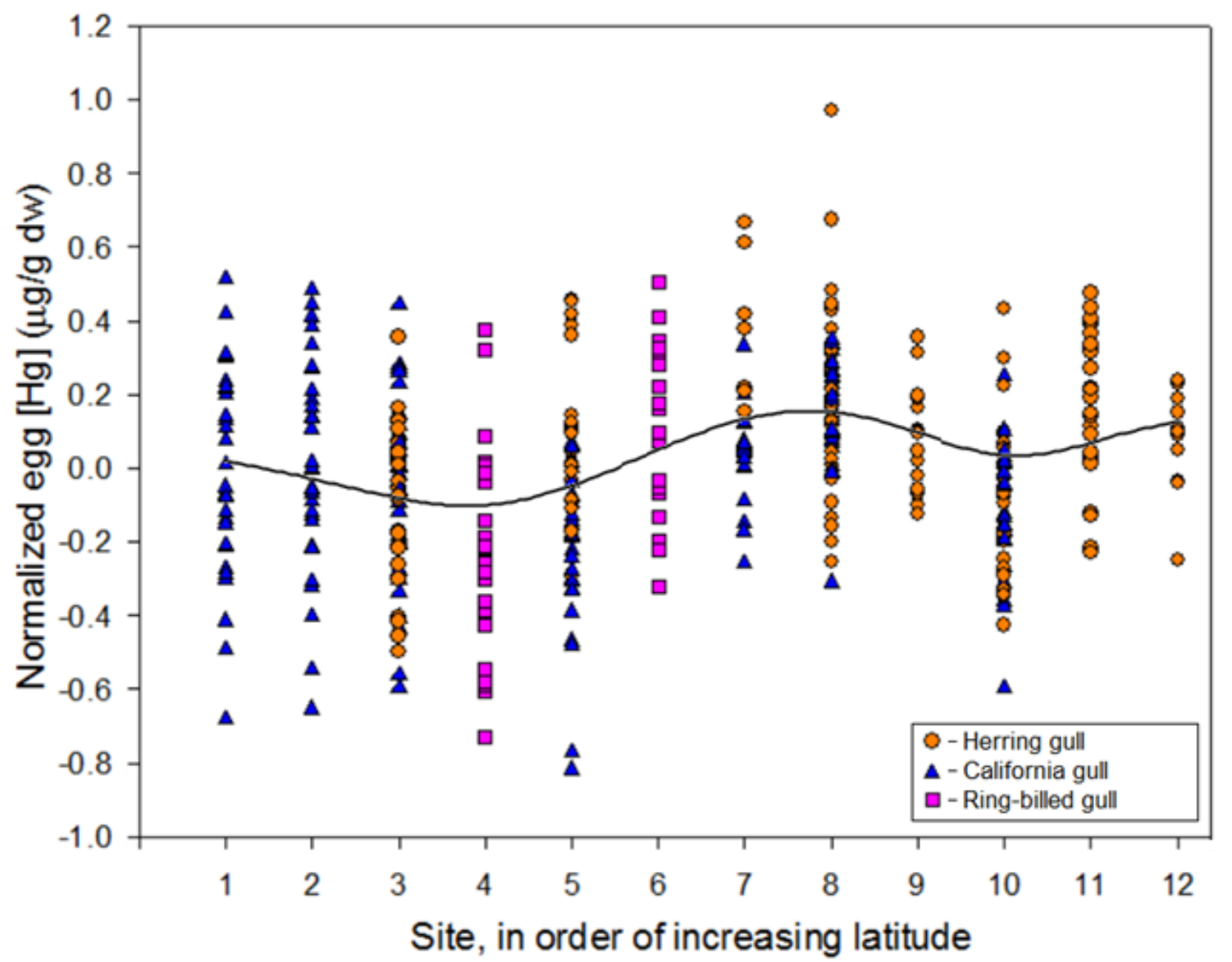

Figure 3.6 Egg THg levels normalized for trophic position and stage of development are weakly correlated with latitude $\left(r_{s}=0.18, P<0.001\right)$. However, distance-weighted least squares curve fitting (black line) indicated that other spatial differences in egg THg levels also exist, i.e. levels at sites 6-8 appear elevated. 


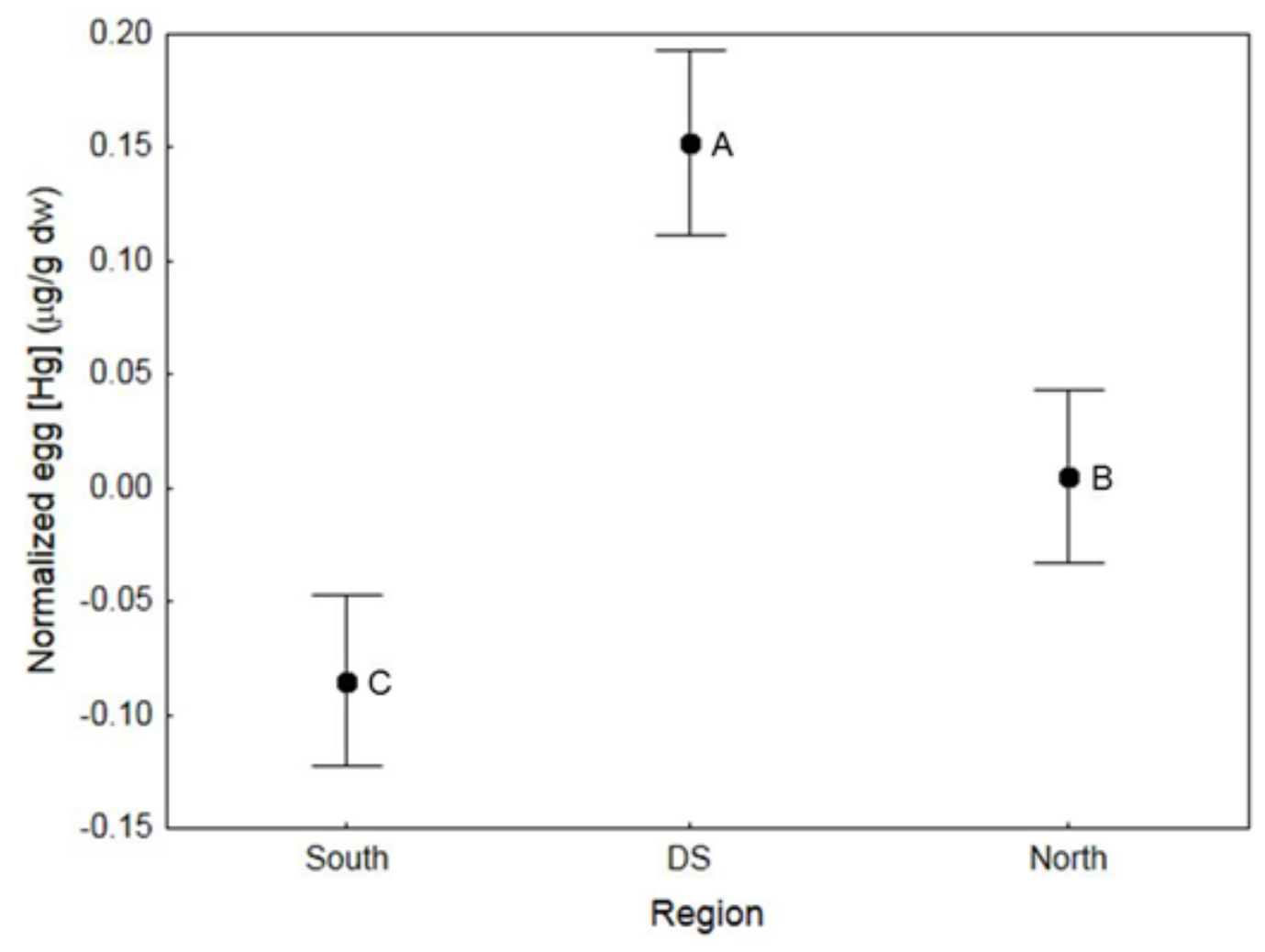

Figure 3.7 Comparison of regional mean $( \pm 95 \%$ confidence interval) egg THg levels normalized for stage of development and trophic position. Sites were categorized into one of three regions: south $\left(<58^{\circ} \mathrm{N}\right.$, sites 1-5), downstream (DS) of the Athabasca River $\left(58.9^{\circ} \mathrm{N}-59.2^{\circ} \mathrm{N}\right.$, sites $\left.6-8\right)$ or north $\left(>59.2^{\circ} \mathrm{N}\right.$, sites $\left.9-12\right)$. Mean normalized egg THg levels were greatest in eggs from DS sites (means with different letters are statistically different, Kruskal-Wallis test, post-hoc comparison of mean ranks $P<0.05$ ). Site numbers are shown in Figure 1.1. 
Water chemistry data are shown in Table 3.1. No clear regional patterns in lake $\mathrm{pH}$ or DOC values were apparent.

Table 3.1 Water chemistry parameters for sites in western Canada.

\begin{tabular}{|l|c|c|c|}
\hline \multicolumn{1}{|c|}{ Site Name } & Degrees of Latitude & $\mathbf{p H}$ & DOC $\mathbf{~ g} / \mathbf{L}$ \\
\hline 1 - Langdon Reservoir & 50.9 & N/A & N/A \\
\hline 2 - Miquelon Lake & 53.3 & 9.4 & 140.0 \\
\hline 3 - Lac La Biche & 54.8 & 8.5 & 9.9 \\
\hline 4 - Preston Lake & 57.4 & 7.9 & 2.4 \\
\hline 5 - Namur Lake & 57.5 & 8.1 & 6.8 \\
\hline 6 - Mamawi Lake & 58.6 & 5.7 & 9.0 \\
\hline 7 - Egg Is, Lake Athabasca & 59.0 & 8.4 & 4.4 \\
\hline 8 - Eastern Lake Athabasca & 59.2 & 8.1 & 7.4 \\
\hline 9 - Rocky Island Lake & 59.2 & 7.9 & 10.5 \\
\hline 10 - Bistcho Lake & 59.7 & 8.5 & 9.8 \\
\hline 11 - Great Slave Lake & 62.8 & 7.9 & 4.8 \\
\hline 12 - Daring Lake & 64.9 & 6.7 & 2.5 \\
\hline
\end{tabular}




\section{Discussion}

Assessing the Relationship Between $\delta^{15} N_{\text {GluPhe }}$ and $\delta^{15} N_{\text {BulkPhe }}$

The highly significant correlation between $\delta^{15} \mathrm{~N}_{\text {GluPhe }}$ and $\delta^{15} \mathrm{~N}_{\text {BulkPhe }}$ indicated that the latter measure could be used as a proxy for trophic position in a similar manner as $\delta^{15} \mathrm{~N}_{\text {GluPhe. }}$ This is important because it circumvents the issue of limited analytical capacity associated with applying the AA-CSIA approach. Normalizing bulk $\delta^{15} \mathrm{~N}$ values generated from the analysis of individuals using a baseline generated from the AA-CSIA of their corresponding pool enhances our ability to apply information gleaned from the AA-CSIA approach to a larger number of samples. This method allows for generation of baseline-

corrected bulk $\delta^{15} \mathrm{~N}$ values in individual samples which can be compared to levels of contaminants measured in the same individuals. Furthermore, this approach bypasses logistical problems associated with collecting primary consumers, e.g. invertebrates such as filter-feeding molluscs, for the generation of baseline isotopic signatures. It also avoids assumptions regarding trophic connections between such primary consumers and top predators which may utilize resources originating from a variety of food web pathways. The isotopic baseline value generated from the analysis of pools reflects the actual baselines integrated by the consumers constituting the pool. Using $\delta^{15} \mathrm{~N}_{\text {GluPhe }}$ or $\delta^{15} \mathrm{~N}_{\text {BulkPhe }}$ values as a proxy of trophic position also circumvents complications of calculating trophic position from AA-CSIA in animals with mixed aquatic algal and terrestrial vascular plant input (for example, see equation 2 in Hebert et al. 2016).

One possible reason for the good correlation between $\delta^{15} \mathrm{~N}_{\text {GluPhe }}$ and $\delta^{15} \mathrm{~N}_{\text {BulkPhe }}$ is that $\delta^{15} \mathrm{~N}$ values in Glu have been found to be well correlated with $\delta^{15} \mathrm{~N}$ values in other trophic amino acids (Seminoff et al. 2012; Bradley et al. 2015; Nielsen et al. 2015). 
Another contributing factor that could be important for eggs is that Glu is an important amino acid constituting total amino acid levels in eggs. In chicken eggs, Glu is the most abundant amino acid, comprising approximately $13 \%$ of total amino acid levels (Lunven et al. 1973); the amino acid compositions of albumen and yolk were found to be similar across five avian orders including domestic fowl (Murphy 1994). Similar trends of predominant Glu composition in eggs have been found in fish (Evans et al. 1996; Gunasekera et al. 1996), molluscs (Lei et al. 2014), as well as total body composition of various small birds and rodents (Kremen et al. 2013). As Glu is present in greater abundance than any other amino acid, it may have played an important role in regulating bulk $\delta^{15} \mathrm{~N}$ values in eggs. Whether this is the case in all types of biological samples merits further study but in a recent study involving fish, trophic position estimates stemming from the use of bulk and source $\delta^{15} \mathrm{~N}$ values were generally consistent with $\delta^{15} \mathrm{~N}_{G l u P h e}$ values (Sackett et al. 2015).

Assessment of Spatial Trends in THg Levels in Gull Eggs from Western Canada Spatial patterns in contaminant levels inferred from biomonitors can be complicated to interpret. Previous work linked latitude with increased $\mathrm{Hg}$ biomagnification in aquatic food webs (Lavoie et al. 2013), citing cold temperatures and low productivity as main drivers. These factors may suppress growth rates in aquatic organisms, minimizing growth dilution of $\mathrm{Hg}$, causing greater accumulation of $\mathrm{Hg}$ in body tissues over time. Furthermore, lower species diversity at higher latitudes may limit prey choice for higher level predators, possibly increasing the trophic transfer efficiency of $\mathrm{Hg}$ through food chains. My study showed that concentrations of $\mathrm{Hg}$ in gull eggs increased 
with latitude. This finding was partly explained by inter-specific and inter-site differences in gull trophic position. For example, the spatial distribution of gull species varied with higher trophic level Herring Gulls predominating in more northerly areas. Given their trophic status, Herring Gulls would have incurred greater exposure to $\mathrm{Hg}$ through their diet, contributing to higher $\mathrm{Hg}$ levels in gull eggs from northern sites. An additional factor that could have been important in causing higher $\mathrm{Hg}$ levels in northern eggs stemmed from the possibility that gulls from more northern sites would have had less access to anthropogenic sources of food resulting in increased consumption of natural aquatic foods, i.e. fish, containing higher $\mathrm{Hg}$ levels. Regardless of the relative importance of these or other mechanisms, bulk $\delta^{15} \mathrm{~N}$ values in eggs were of little use in explaining latitudinal increases in egg Hg levels. This was due to the fact that bulk $\delta^{15} \mathrm{~N}$ values did not account for baseline differences in $\delta^{15} \mathrm{~N}$ across the ecosystems being sampled. Egg $\delta^{15} \mathrm{~N}$ values adjusted for baseline exhibited an obvious increase with latitude emphasizing the importance of considering latitudinal differences in trophic position when interpreting spatial patterns in egg Hg levels. When egg concentrations were normalized for diet, the latitudinal relationship with egg $\mathrm{Hg}$ levels was still present but its significance was greatly reduced and other spatial patterns in diet-normalized egg Hg concentrations were revealed, i.e. highest egg $\mathrm{Hg}$ levels were observed at sites in receiving waters of the Athabasca River. Higher $\mathrm{Hg}$ levels at northern versus southern sites may have been due to a variety of factors including higher $\mathrm{Hg}$ deposition in the north or differences in processes regulating biomagnification as described by Lavoie et al. (2013). Elucidating the relative importance of these and other factors requires further research. 
Greater diet-normalized $\mathrm{Hg}$ levels in eggs collected from sites in receiving waters of the Athabasca River may have reflected a variety of factors including long-range and regional transport of $\mathrm{Hg}$ (see Hebert et al. 2013). However, given that differences in egg Hg levels were detected over relatively small spatial scales, I focus on two possibilities here: 1) local $\mathrm{Hg}$ sources and 2) spatial differences in processes regulating $\mathrm{Hg}$ bioavailability. Based on deposition patterns, the Athabasca oil sands are a source of airborne environmental contaminants to waterbodies up to $90 \mathrm{~km}$ from bitumen upgrading facilities (Kelly et al. 2010). Data from accumulated spring-time snowpacks (representing deposition from mid-November to March) have also suggested that the oil sands industry was a source of atmospheric deposition of bioavailable $\mathrm{MeHg}$ to local landscapes and waterbodies (Kirk et al. 2014). Highest levels were observed at sites within the major oil sands development area, decreasing in concentration in a bullseye pattern with lowest concentrations at the most distant sites (e.g. Peace-Athabasca Delta). However, a study using sediment cores from a precipitation-fed lake to establish long-term metal deposition patterns in the Peace-Athabasca Delta found no evidence of a relationship between the expansion of the oil sands industry and $\mathrm{Hg}$ deposition (Wiklund et al. 2012). Atmospheric deposition of oil sands-related contaminants is only one possible avenue of $\mathrm{Hg}$ transfer to the environment. Large containment structures associated with oil sands development, i.e. tailings ponds, contain a mixture of metals and various organic compounds (e.g. naphthenic acids, polycyclic aromatic hydrocarbons) (Allen 2008; Frank et al. 2014; Galarneau et al. 2014). Tailings ponds may act as a source of contaminants through seepage to groundwater or to the Athabasca River (Frank et al. 2014). Hg availability to biota may be influenced by Hg transport down the Athabasca River to the Peace-Athabasca Delta and Lake 
Athabasca. Since wet deposition is an important source of $\mathrm{Hg}$ to watersheds, transport through precipitation and runoff as well as watershed hydrology may be important. However, contaminant signatures in sediment samples from the lower Athabasca River have also been attributed to natural weathering patterns of bituminous deposits (Akre et al. 2004). Furthermore, the Peace-Athabasca Delta (PAD) is served by two major waterways - the Athabasca and Peace Rivers. The Athabasca River is a significant source of water and sediment to the PAD (Timoney 2013) and, therefore, is important in terms of regulating possible riverine transport of contaminants to the delta. However, dams and reservoir creation on the Peace River may be affecting $\mathrm{Hg}$ bioavailability by creating conditions conducive to $\mathrm{Hg}$ methylation. Flooding events and water table fluctuations have been linked to increased concentrations of total $\mathrm{Hg}$ and $\mathrm{MeHg}$, including in wetlands in the Athabasca oil sands region (Oswald and Carey 2016). However, existing data regarding concentrations of $\mathrm{MeHg}$ in various matrices (i.e. water, sediment, invertebrates, fish) from the Peace River are among the lowest in Canada (Site C Environmental Impact Statement 2013 ) indicating that the Peace River may be a less important source of $\mathrm{Hg}$ for the PAD. Clearly, the degree to which the Athabasca River is important in transporting $\mathrm{Hg}$ to downstream sites requires further investigation. Given the relatively rapid development of oil sands activities along the Athabasca River it might be reasonable to expect temporal changes in levels of oil sands-related contaminants, e.g. $\mathrm{Hg}$, in biota. However, $\mathrm{Hg}$ temporal trends in downstream biota are equivocal with either no (fish, Evans and Talbot 2012) or limited evidence of an increase (birds, Hebert et al. 2013) through time. Hebert et al. (2011) previously suggested that the Athabasca River may be serving as a potential source of environmental contaminants to colonial waterbirds nesting at downstream 
locations. Results presented here do not contradict that possibility given that the highest egg Hg levels were observed in samples collected downstream of the Athabasca River, but other factors may also be contributing to these spatial trends.

Previous work found that methylation rates were more important than inorganic $\mathrm{Hg}$ loading when determining fish MeHg exposure (Eagles-Smith et al. 2016). Under organicrich, anaerobic conditions, sulfur-reducing bacteria mediate the transformation of inorganic $\mathrm{Hg}$ to $\mathrm{MeHg}$. Enhanced bacterial activity and subsequent methylation rates have been observed under low $\mathrm{pH}$, low salinity and high levels of dissolved organic matter (Ullrich et al. 2001). Wetlands are a particularly important site for $\mathrm{MeHg}$ production in aquatic systems, with high methylation rates observed in various wetland ecosystems, including boreal forests (St Louis et al. 1994) and tropical floodplains (Lazaro et al. 2016). Environmental conditions in the Peace-Athabasca Delta may provide more favourable conditions for Hg methylation compared to 'northern' or 'southern' sites. Further research is required to investigate this possibility. The water chemistry parameters measured at my sites (Table 3.1) did not explain my results. Previous studies identified water chemistry values that significantly correlated with high $\mathrm{Hg}$ concentrations in fish, e.g. $\mathrm{pH}<6.0$, DOC $>4 \mathrm{mg} / \mathrm{L}$ (Chen et al. 2005; Driscoll et al. 2007). Values of $\mathrm{pH}$ for my water samples were all above 6.0. Though all DOC levels were greater than $4 \mathrm{mg} / \mathrm{L}$, no clear relationships were apparent with egg Hg levels. In fact, Hg levels in eggs from the PAD/Lake Athabasca region were highest, yet water samples from the Lake Athabasca sites had some of the lowest DOC levels. Clearly, the degree to which water chemistry influences Hg levels in waterbirds in this region requires further study. 
Progress has been made in evaluating levels of contaminants in the oil sands region; however, data from biological monitoring programs are still limited. A variety of ecological and physical factors are likely interacting in complex ways to regulate $\mathrm{Hg}$ bioavailability in this region. Ongoing efforts to integrate data from biotic and abiotic monitoring programs are critical to conclusively elucidate the factors underlying the spatial differences in egg Hg levels highlighted here. Such efforts will benefit from the application of new methods, such as AA-CSIA, to enhance our ability to interpret data generated from environmental monitoring activities. Previous studies involving birds in both controlled and field settings were able to accurately predict trophic position based upon Phe and Glu $\delta^{15} \mathrm{~N}$ values (Lorrain et al. 2009; McMahon et al. 2015; Hebert et al. 2016). The present study demonstrates the utility of a modified AA-CSIA approach using baseline-adjusted bulk $\delta^{15} \mathrm{~N}$ values to normalize egg $\mathrm{Hg}$ data for trophic position. This approach generated new insights into spatial patterns of biomagnifying contaminants in the environment. Removing the influence of trophic position allowed for a more accurate assessment of factors regulating $\mathrm{Hg}$ levels in wildlife, providing insights into potential $\mathrm{Hg}$ sources and/or processes regulating $\mathrm{Hg}$ bioavailability. The case study presented here is but one example of the possible utility of the AA-CSIA approach to contaminants research and I envision that it will be broadly applied in future contaminant monitoring studies. 
CHAPTER FOUR

\section{GENERAL SUMMARY}


Gull eggs have been used to establish mercury $(\mathrm{Hg})$ spatial and temporal trends in a variety of environmental monitoring programs across Canada (Weseloh et al. 2011; Burgess et al. 2013; Braune et al. 2015; Elliott and Elliott 2016). The continuation and improvement of these programs is crucial in providing accurate insights into exposure, transport, and fate of this toxic contaminant. My objective was to explore the utility of eggs of various gull species to establish spatial patterns of $\mathrm{Hg}$ in western Canada where data are sparse. My research focused on evaluating factors that may affect the utility of waterbird eggs to provide an indication of spatial patterns in $\mathrm{Hg}$ bioavailability. I paid particular attention to two factors that could influence the interpretation of dry weight $\mathrm{Hg}$ concentrations in eggs: 1) stage of egg incubation and 2) trophic position of the laying female as indicated by egg isotope values. Below, I discuss key findings from my research, the novelty of my work and discuss possible avenues for future research.

Studies using dry weight $\mathrm{Hg}$ concentrations in eggs assume that dry mass (e.g. lipids) of egg contents does not change through incubation and that expressing concentrations on a dry weight basis adjusts for any changes that may occur in egg mass throughout the incubation period. Through egg injection and artificial incubation studies using chicken eggs, I found that $\mathrm{Hg}$ concentrations may be biased high for samples analyzed at later stages of development (Chapter 2). My experiment was novel in that I was able to validate the utility of an incubation adjustment factor based on egg morphological parameters to adjust dry weight $\mathrm{Hg}$ concentrations for stage of incubation in eggs. I used a unique dataset $(n=212)$ of individual gull eggs collected over a two year period for which both egg morphology and incubation stage estimates were available. This allowed me to test the degree to which stage of incubation and an incubation adjustment 
factor (based on egg morphology) were correlated. The strong correlation between the two metrics justified my use of the incubation adjustment factor to eliminate the influence of stage of incubation on dry weight $\mathrm{Hg}$ concentrations. This adjustment factor approach is a straight-forward way to account for stage of development when assessing $\mathrm{Hg}$ levels in avian eggs and should see wide application in studies of this nature. However, further work could be done to evaluate more precisely the relationship between dry weight $\mathrm{Hg}$ concentrations in eggs and stage of incubation using larger sample sizes and more frequent sampling. Given that embryonic metabolic rate increases exponentially after midincubation (Vleck et al. 1980), it would be useful to more accurately determine how egg $\mathrm{Hg}$ concentrations track metabolic changes. Furthermore, although metabolic increases with stage of incubation are likely conservative among species (Vleck et al. 1980), my study was based upon eggs of a precocial species. It would be useful to conduct similar studies on semi-precocial and altricial species to evaluate the universality of the results reported here.

In Chapter 3, I presented a novel application of amino acid compound-specific stable nitrogen isotope analysis for assessing spatial trends in $\mathrm{Hg}$. My results demonstrated the utility of this approach, suggesting that gulls breeding at colonies located in receiving waters of the Athabasca River were subject to higher $\mathrm{Hg}$ exposure, resulting in elevated egg Hg levels at those sites.

Utilizing top predators for spatial studies investigating contaminant bioavailability requires careful consideration of trophic position of study organisms. This is typically addressed through application of stable nitrogen isotopes, generally by measuring $\delta^{15} \mathrm{~N}$ values in bulk tissue. The main drawback of this method lies in its inability to generate a 
baseline $\delta^{15} \mathrm{~N}$ value to normalize predator $\delta^{15} \mathrm{~N}$ values across space (or time). Generation of $\delta^{15} \mathrm{~N}$ values for individual amino acids through the application of AA-CSIA allowed me to establish both $\delta^{15} \mathrm{~N}$ baselines and trophic position estimates using the same sample. A drawback of this approach is its expense thereby limiting its application to relatively few samples. A key finding from my work was the highly significant correlation between $\delta^{15} \mathrm{~N}_{\text {GluPhe }}$ and $\delta^{15} \mathrm{~N}_{\text {BulkPhe }}$ which indicated that the latter measure could be used as a proxy for trophic position in a similar manner as $\delta^{15} \mathrm{~N}_{\mathrm{GluPh}}$. This highlights the possibility of greatly expanding the application of the AA-CSIA approach by generating baseline $\delta^{15} \mathrm{~N}$ values from the analysis of pooled samples and applying these baselines to bulk $\delta^{15} \mathrm{~N}$ values generated for individuals. This AA-CSIA-based approach allows an accounting for dietary variation across individuals while not requiring characterization of nitrogen isotope values in primary consumers to generate isotopic baselines.

The application of AA-CSIA to avian-based contaminant monitoring programs is still in its infancy. Studies involving spatial comparisons of bioaccumulating pollutants on the Great Lakes, for example, have noted dietary differences in birds nesting at different colonies and have hypothesized regarding the degree to which these dietary differences contribute to spatial differences in levels of emerging contaminants such as perfluorinated compounds (Letcher et al. 2015). Furthermore, the diverse landscapes and latitudinal gradients covered in these programs may require a variety of bird species to be used. Comparing contaminant levels in multiple species with different feeding ecologies is not uncommon (Gewurtz et al. 2016; Su et al. 2017). I demonstrated that through the AACSIA approach, the influence of diet/trophic position on interpretation of spatial trends in biomagnifying contaminants such as $\mathrm{Hg}$ can largely be eliminated. This highlights possible 
practical applications of my approach, and may serve to help interpret data from ongoing monitoring programs such as Environment and Climate Change Canada's Chemicals Management Plan. In the context of my research, application of the AA-CSIA approach provided new insights into spatial patterns in Hg levels in eggs of waterbirds nesting in western Canada. In particular, it highlighted regional differences in egg $\mathrm{Hg}$ levels that were related to latitude and watershed influences, i.e. sites in receiving waters of the Athabasca River had the highest egg Hg levels. This latter observation identified two specific research needs: 1) information is required to determine the degree to which the Athabasca River is acting as a source of $\mathrm{Hg}$ to downstream environments and 2) there is a need to study possible spatial differences in Hg methylation (particularly in the Peace-Athabasca Delta) to better understand the degree to which processes associated with $\mathrm{Hg}$ cycling are influencing $\mathrm{Hg}$ levels in wildlife. Clearly, application of the AA-CSIA approach to environmental contaminant studies is just beginning but, as I demonstrate here, it will likely be a fruitful area for further investigation. 


\section{References}

Ackerman, J.T., Herzog, M.P., \& Schwarzbach, S.E. (2013). Methylmercury is the dominant form of mercury in bird eggs: a synthesis. Environmental Science \& Technology, 47: 2052-2060.

Ackerman, J.T., Eagles-Smith, C.A., Herzog, M.P., Yee, J.L., \& Hartman, C.A. (2016). Egg-laying sequence influences egg mercury concentrations and egg size in three bird species: Implications for contaminant monitoring programs. Environmental Toxicology and Chemistry, 35: $1458-1469$.

Akearok, J.A., Hebert, C.E., Braune, B.M., \& Mallory, M.L. (2010). Inter- and intraclutch variation in egg mercury levels in marine bird species from the Canadian Arctic. Science of the Total Environment, 408: 836-840.

Akre, C.J., Headley, J.V., Conly, F.M., Peru, K.M., \& Dickson, L.C. (2004). Spatial patterns of natural polycyclic aromatic hydrocarbons in sediment in the lower Athabasca River. Journal of Environmental Science and Health, Part A, 39: 1163-1176.

Alberta Health. (2007). Wood Buffalo Environmental Association Human Exposure Monitoring Program (HEMP). Methods report and 2005 monitoring year results. Wood Buffalo Environmental Monitoring Association, Fort McMurray, AB, Canada.

Allen, E.W. (2008). Process water treatment in Canada's oil sands industry: I. Target pollutants and treatment objectives. Journal of Environmental Engineering and Science, 7: 123-138.

Altabet, MA. (2001). Nitrogen isotopic evidence for micronutrient control of fractional $\mathrm{NO}_{3}{ }^{-}$utilization in the equatorial Pacific. Limnology and Oceanography, 46: 368380 .

Ar, A. \& Rahn, H. (1980). Water in the avian egg - Overall budget of incubation. American Zoologist, 20: 373-384.

Birds of North America. Rodewald, P. Ed. Ithaca: Cornell Laboratory of Ornithology; Retrieved from The Birds Of North America: https://birdsna.org; MAR 2017.

Bond, A.L., \& Diamond, A.W. (2010). Nutrient allocation for egg production in six Atlantic seabirds. Canadian Journal of Zoology, 88: 1095-1102.

Bradley, C.J, Wallsgrove, N.J., Choy, C.A., Drazen, J.C., Hetherington, E.D., Hoen, D.K., \& Popp, B.N. (2015). Trophic position estimates of marine teleosts using amino acid compound specific isotopic analysis. Limnology and Oceanography: Methods, 13: 476-493. 
Braune, B.A. (2007). Temporal trends of organochlorines and mercury in seabird eggs from the Canadian Arctic, 1975-2003. Environmental Pollution, 148: 599-613.

Braune, B.A., Scheuhammer, A.M., Crump, D., Jones, S., Porter, E., \& Bond, A. (2012). Toxicity of methylmercury injected into eggs of thick-billed murres and arctic terns. Ecotoxicology, 21:2143-2152.

Braune, B.A, Chetelat, J., Amyot, M., Brown, T., Clayden, M., Evans, M., Fisk, A., Gaden, A., Girard, C., Hare, A., Kirk, J., Lehnherr, I., Letcher, R., Loseto, L., Macdonald, R., Mann, E., McMeans, B., Muir, D., O’Driscoll, N., Poulain, A., Reimer, K., \& Stern, G. (2015). Mercury in the marine environment of the Canadian Arctic: Review of recent findings. Science of the Total Environment, 509: 67-90.

Burgess N.M., Bond, A.L., Hebert, C.E., Neugebauer, E., \& Champoux, L. (2013). Mercury trends in herring gull (Larus argentatus) eggs from Atlantic Canada, 1972- 2008: Temporal change or dietary shift? Environmental Pollution, 172: 216-222.

Butterworth, E., Leach, A., Gendron, M., Pollard, B., \& Stewart, G.R. (2002). PeaceAthabasca Delta waterbird inventory program: 1998-2001 final report. Ducks Unlimited Canada, Edmonton, AB.

Cabana, G., \& Rasmussen, J.B. (1994). Modelling food chain structure and contaminant bioaccumulation using stable nitrogen isotopes. Nature, 372: 255-257.

Canadian Association of Petroleum Producers (CAPP). (2016). Crude oil: forecast, markets and transportation, p. 5. <http://www.capp.ca/publications-andstatistics/publications/284950>.

Carr, M.K., Jardine, T.D., Doig, L.E., Jones, P.D., Bharadwaj, L., Tendler, B., Chetelat, J., Cott, P., \& Lindenschmidt K.-E. (2017). Stable sulfur isotopes identify habitatspecific foraging and mercury exposure in a highly mobile fish community. Science of the Total Environment, http://dx.doi.org/10.1016/j.scitotenv. 2017.02.013

Chen, C.Y., Stemberger, R.S., Kamman, N.C., Mayes, B.M., Folt, C.L. (2005). Patterns of $\mathrm{Hg}$ bioaccumulation and transfer in aquatic food webs across multi-lake studies in the northeast US. Ecotoxicology, 14: 135-147.

Chikaraishi, Y., Kashiyama, Y., Ogawa, N. O., Kitazato, H., \& Ohkouchi, N. (2007). Metabolic control of nitrogen isotope composition of amino acids in macroalgae and gastropods: implications for aquatic food web studies. Marine Ecology Progress Series, 342: 85-90. 
Chikaraishi, Y., Ogawa, N.O., Kashiyama, Y., Takano, Y., Suga, H., Tomitani, A., Miyashita, H., Kitazato, H., \& Ohkouchi, N. (2009). Determination of aquatic food-web structure based on compound-specific nitrogen isotopic composition of amino acids. Limnology and Oceanography Methods, 7: 740-750.

Chikaraishi, Y., Steffan, S.A., Ogawa, N.O., Ishikawa, N.F., Sasaki, Y., Tsuchiya, M., \& Ohkouchi, N. (2014). High-resolution food webs based on nitrogen isotopic composition of amino acids. Ecology and Evolution, 4: 2423-2449.

Clarkson, T.W. (1992). Mercury: Major issues in environmental health. Environmental Health Perspectives, 100: 31-38.

Connolly, R.M., Guest, M.A., Melville, A.J., Oakes, J.A. (2004). Sulfur stable isotopes separate producers in marine food-web analysis. Oecologia, 138: 161-167.

Cruz-Martinez, L., Fernie, K.J., Soos, C., Harner, T., Getachew, F., \& Smits, J.E.G. (2014). Detoxification, endocrine, and immune responses of tree swallow nestlings exposed to air contaminants from the Alberta oil sands. Science of the Total Environment, 502: 8-15.

Dawson, T.E., \& Brooks, P.D. (2001). Fundamentals of stable isotope chemistry and measurement. In Stable Isotope Techniques in the Study of Biological Processes and Functioning of Ecosystems; Unkovich, M. Eds; Kluwer Academic Publishers, Dordrecht, Netherlands, pp. 1-19.

DeNiro, M.J., \& Epstein, S. (1978). Influence of diet on the distribution of carbon isotopes in animals. Geochemica et Cosmochimica Acta, 42: 495-506.

DeNiro, M.J., \& Epstein, S. (1981). Influence of diet on the distribution of nitrogen isotopes in animals. Geochemica et Cosmochimica Acta, 45: 341-351.

Driscoll, C.T., Han, Y.J., Chen, C.Y., Evers, D.C., Lambert, K.F., Holsen, T.M., Kamman, C.N., \& Munson, R.K. (2007). Mercury contamination in forest and freshwater ecosystems in the northeastern United States. Bioscience, 57: 17-28.

Eagles-Smith, C.A., Acherkam, J.T., Willacker, J.J., Tate, M.T., Lutz, M.A., Fleck, J.A., Stewart, A.R., Wiener, J.G., Evers, D., Lepak, J.M., David, J.A., \& Pritz, C.F. (2016). Spatial and temporal patterns of mercury concentrations in freshwater fish across the Western United States and Canada. Science of the Total Environment, 568: 1171-1184.

EIA. (2015). US Energy Information and Administration. Energy Sector Analysis: Canada. $<$ http://www.eia.gov/beta/international/analysis.cfm?iso=CAN $>$. 
Elliott, K.H., \& Elliott, J.E. (2016). Origin of sulfur drives spatial and temporal mercury trends in seabird eggs from Pacific Canada 1968-2015. Environmental Science and Technology, 50: 13380-13386.

Evans, R.P., Parrish, C.C., Brown, J.A., \& David, P.J. (1996). Biochemical composition of eggs from repeat and first-time spawning captive Atlantic halibut (Hippoglossu hiypoglossus). Aquaculture, 139: 139-149.

Evans, M.S., \& Talbot, A. (2012). Investigations of mercury concentrations in walleye and other fish in the Athabasca River ecosystem with increasing oil sands developments. Journal of Environmental Monitoring, 14: 1989-2003.

Evers, D.C., Taylor, K.M., Major, A., Taylor, R.J., Poppenga, R.H., \& Scheuhammer, A.M. (2003). Common loon eggs as indicators of methylmercury availability in North America. Ecotoxicology, 12: 69-81.

Frank, R.A., Roy, J.W., Bickerton, G., Rowland, S.J., Headley, J.V., Scarlett, A.G., West, C.E., Peru, K.M., Parrott, J.L., Conly, F.M., \& Hewitt, L.M. (2014). Profiling oil sands mixtures from industrial development and natural groundwaters for source identification. Environmental Science \& Technology, 48: 2660-2670.

Fry, B., Mumford, P.L., Tam, F., Fox, D.D., Warren, G.L., Havens, K.E., \& Steinman, A.D. (1999). Trophic position and individual feeding histories of fish from Lake Okeechobee, Florida. Canadian Journal of Fisheries and Aquatic Sciences, 54: 590-600.

Fry, B. (2006). Using stable isotope tracers. In Stable Isotope Ecology; Springer; New York, NY, pp. 47.

Galarneau, E., Hollebone, B.P., Yang, Z., \& Schuster, J. (2014). Preliminary measurement-based estimates of PAH emissions from oil sands tailings ponds. Atmospheric Environment, 97: 332-335.

Germain, L. R., Koch, P. L., Harvey, J., \& McCarthy, M. D. (2013). Nitrogen isotope fractionation in amino acids from harbor seals: implications for compoundspecific trophic position calculations. Marine Ecology Progress Series, 482: 265277.

Gewurtz, S.B., Martin, P.A., Letcher, R.J., Burgess, N.M., Champoux, L., Elliott, J.E., \& Weseloh, D.V.C. (2016). Spatio-temporal trends and monitoring design of perfluoroalkyl acids in the eggs of gull (Larid) species from across Canada and parts of the United States. Science of the Total Environment, 565: 440-450.

Giesy, J.P., Anderson, J.C., \& Wiseman, S.B. (2010). Alberta oil sands development. Proceedings of the National Academy of Sciences U.S.A., 107: 951-952. 
Gill, F.B. (2007). Avian life histories: Bird sex. In Ornithology; Tenney, S. Ed; W.H. Freeman and Company, New York, NY; pp. 428.

Guide to Eating Ontario Sport Fish. (2016). Fish Contaminant Monitoring Program, Etobicoke, ON. $<$ https://ontario.ca/fishguide $>$.

Gunasekera, R.M., Shim, K.F., \& Lam, T.J. (1996). Effect of dietary protein level on spawning performance and amino acid composition of eggs of Nile tilapia, Oreochromis noliticus. Aquaculture, 146: 121-134.

Hannides, C.C.S., Popp, B.N., Landry, M.R., \& Graham, B.S. (2009). Quantification of zooplankton trophic position in the North Pacific Subtropical Gyre using stable nitrogen isotopes. Limnology and Oceanography, 54: 50-61.

Harris, M.P. (1964). Aspects of the breeding biology of gulls. Ibis, 106: 432-456.

Hebert, C.E., Norstrom, R.J., \& Weseloh, D.V. (1999). A quarter century of environmental surveillance: the Canadian Wildlife Service's Great Lakes Herring Gull Monitoring Program. Environmental Reviews, 7: 147-166.

Hebert, C.E., Hobson, K.A., Shutt, J.L. (2000). Changes in food web structure affect rate of PCB decline in herring gull (Larus argentatus) eggs. Environmental Science \& Technology, 34: 1609-1614.

Hebert, C.E., \& Wassenaar, L.I. (2001). Stable nitrogen isotopes in waterfowl feathers reflect agricultural land use in western Canada. Environmental Science \& Technology, 35: 3482-3487.

Hebert, C.E., \& Weseloh, D.V. (2006). Adjusting for temporal change in trophic position results in reduced rates of contaminant decline. Environmental Science \& Technology, 40: 5624-5628.

Hebert, C.E., Bur, M., Sherman, D., \& Shutt, J.L. (2008). Sulfur isotopes link overwinter habitat use and breeding condition in double-crested cormorants. Ecological Applications, 18: 561-567.

Hebert, C.E., Weseloh, D.V., MacMillan, S., Campbell, D., \& Nordstrom, W. (2011). Metals and polycyclic aromatic hydrocarbons in colonial waterbird eggs from Lake Athabasca and the Peace-Athabasca Delta, Canada. Environmental Toxicology \& Chemistry, 30: 1178-1183.

Hebert, C.E., Campbell, D., Kindopp, R., MacMillan, S., Martin, P., Neugebauer, E., Patterson, L., \& Shatford, J. (2013). Mercury trends in colonial waterbird eggs downstream of the oil sands region of Alberta, Canada. Environmental Science \& Technology, 47: 11785-11792. 
Hebert, C.E., Popp, B.N., Fernie, K.J., Ka'apu-Lyons, C., Rattner, B.A., \& Wallsgrove, N. (2016). Amino acid-specific stable nitrogen isotope values in avian tissues: Insights from captive American Kestrels and wild Herring Gulls. Environmental Science \& Technology, 50: 12928-12937.

Heinz, G.H. (1979). Methylmercury: Reproductive and behavioral effects on three generations of mallard ducks. Journal of Wildlife Management, 43: 394- 401.

Heinz, G.H., \& Hoffmann, D.J. (2004). Mercury accumulation and loss in mallard eggs. Environmental Toxicology and Chemistry, 23: 222-224.

Heinz, G.H., Hoffman, D.J., Kondrad, S.L., \& Erwin, C.A. (2006). Factors affecting the toxicity of methylmercury injected into eggs. Archives of Environmental Contamination and Toxicology, 50: 264 - 279.

Heinz, G.H., Hoffmann, D.J., Klimstra, J.D., Stebbins, K.R., Kondrad, S.L., \& Erwin, C.A. (2009a). Species differences in the sensitivity of avian embryos to methylmercury. Archives of Environmental Contamination and Toxicology, 56: 129-138.

Heinz, G.H., Hoffman, D.J., Klimstra, J.D., \& Stebbins, K.R. (2009b). Rapid increases in mercury concentrations in the eggs of mallards fed methylmercury. Environmental Toxicology and Chemistry, 28: 1979-1981.

Hesslein, R.H., Capel, M.J., Fox, D.E., \& Hallard, K.A. (1991). Stable isotopes of sulfur, carbon and nitrogen as indicators of trophic level and fish migration in the lower Mackenzie River basin, Canada. Canadian Journal of Fisheries and Aquatic Sciences, 48: 2258-2265.

Hobson, K.A., Hughes, K.D., \& Ewins, P.J. (1997). Using stable-isotope analysis to identify endogenous and exogenous sources of nutrients in eggs of migratory birds: Applications to Great Lakes contaminants research. The Auk, 114: 467478.

Hobson, K.A., Atwell, L., Wassenaar, L.I., \& Yerkes, T. (2004). Estimating endogenous nutrient allocations to reproduction in Redhead Ducks: a dual isotope approach using $\delta \mathrm{D}$ and $\delta^{13} \mathrm{C}$ measurements of female and egg tissues. Functional Ecology, 18: $737-747$.

Hoen, D.K., Kimb, S.L., Hussey, N.E., Wallsgrove, N.J., Drazen, J.C., \& Popp, B.N. (2014). Amino acid ${ }^{15} \mathrm{~N}$ trophic enrichment factors of four large carnivorous fishes. Journal of Experimental Marine Biology and Ecology, 453: 76-83.

Hyslop, E. (1980). Stomach contents analysis-a review of methods and their application. Journal of Fish Biology, 17: 411-429. 
Jaffe, D., \& Strode, S. (2008). Sources, fate and transport of atmospheric mercury from Asia. Environmental Chemistry, 5: 121-126.

Kambamanoli-Dimou, A., Kamarianos, A., \& Kilikidis, S. (1991). Transfer of methylmercury to hens' eggs after oral administration. Bulletin of Environmental Contamination and Toxicology, 46: 128-33.

Karsh, K.L., Trull, T.W., Lourey, M.J., \& Sigman, D.M. (2003). Relationship of nitrogen isotope fractionation to phytoplankton size and iron availability during the Southern Ocean Iron Release Experiment (SOIREE). Limnology and Oceanography, 48: 1058-1068.

Kelly, J.F. (2000). Stable isotopes of carbon and nitrogen in the study of avian and mammalian trophic ecology. Canadian Journal of Zoology, 78: 1-27.

Kelly, E.N., Schindler, D.W., Hodson, P.V., Short, J.W., Radmanovich, R., \& Nielsen, C.C. (2010). Oil sands development contributes elements toxic at low concentrations to the Athabasca River and its tributaries. Proceedings of the National Academy of Sciences U.S.A., 107: 16178-16183.

Kirk, J.L., Muir, D.C.G., Gleason, A., Wang, X.W., Lawson, G., Frank, R.A., Lehnherr, I., \& Wrona, F. (2014). Atmospheric deposition of mercury and methylmercury to landscapes and waterbodies of the Athabasca Oil Sands region. Environmental Science \& Technology, 48: 7374-7383.

Klaassen, M. (2001). Ornithology: Arctic waders are not capital breeders. Nature, 413: 794-794.

Kremen, N.A., Calvert, C.C., Larsen, J.A., Baldwin, R.A., Hahn, T.P., \& Fascetti, A.J. (2013). Body composition and amino acid concentrations of select birds and mammals consumed by cats in northern and central California. Journal of Animal Science, 91: 1270-1276.

Kuyt, E. (1993). Whooping Crane, Grus americana, home-range and breeding range expansion in Wood Buffalo National Park: 1970-1991. Canadian Field Naturalist, 107: $1-12$.

Lavoie, R.A., Jardine, T.D., Chumchal, M.M., Kidd, K.A., \& Campbell, L.M. (2013). Biomagnification of mercury in aquatic food webs: A worldwide meta-analysis. Environmental Science \& Technology, 47: 13385-13394.

Layman, C.A., Araujo, M.S., Boucek, R., Hammerschlag-Peyer, C.M., Harrison, E., Jud, Z.R., Matich, P., Rosenblatt, A.E., Vaudo, J.J., Yeager, L.A., Post., D.M., \& Bearhop, S. (2012). Applying stable isotopes to examine food-web structure: an overview of analytical tools. Biological Reviews, 87: 545-562. 
Lazaro, W.L., Diez, S., da Silva, C.J., Ignacio, A.R.A., \& Guimaraes, J.R.D. (2016). Waterscape determinants of net mercury methylation in a tropical wetland. Environmental Research, 150: 438-445.

Lei, S.H., Zhang, X.M., Zhang, P.D., \& Ikeda, Y. (2014). Biochemical composition of cuttlefish (Sepia esculenta) eggs during embryonic development. Molluscan Research, 34: 1-9.

Letcher, R.J., Su, G., Moore, J.N., Williams, L.L., Martin, P.A., de Solla, S.R., \& Bowerman, W.W. (2015). Perfluorinated sulfonate and carboxylate compounds and precursors in herring gull eggs from across the Laurentian Great Lakes of North America: Temporal and recent spatial comparisons and exposure implications. Science of the Total Environment, 538: 468-477.

Lorrain, A., Graham, B., Menard, F., Popp, B., Bouillon, S., van Breugel, P., \& Cherel, Y. (2009). Nitrogen and carbon isotope values of individual amino acids: a tool to study foraging ecology of penguins in the Southern Ocean. Marine Ecology Progress Series, 391: 293-306.

Lott, C.A., Meehan, T.D., \& Heath, J.A. (2003). Estimating the latitudinal origins of migratory birds using hydrogen and sulfur stable isotopes in feathers: influence of marine prey base. Oecologia, 134: 505-510.

Lunven, P., Le Clement de St Marcq, C., Carnovale, E., \& Fratoni, A. (1973). Amino acid composition of hen's egg. British Journal of Nutrition, 30: 189-194.

MacAvoy, S.E., Macko, S.A., McIninch, S.P., \& Garman, G.C. (2000). Marine nutrient contributions to freshwater apex predators. Oecologia, 122: 568-573.

McCarthy, M.D., Benner, R., Lee, C., \& Fogel, M.L. (2007). Amino acid nitrogen isotopic fractionation patterns as indicators of heterotrophy in plankton, particulate, and dissolved organic matter. Geochimica et Cosmochimica Acta, 71: $4727-4744$.

McClelland, J. W., \& Montoya, J. P. (2002). Trophic relationships and the nitrogen isotopic composition of amino acids in plankton. Ecology, 83: 2173-2180.

MCFN (Mikisew Cree First Nation). (2014). Petition to the World Heritage Committee requesting Inclusion of Wood Buffalo National Park on the List of World Heritage in Danger, Fort McMurray, AB.

McMahon, K.W., Polito, M.J., Abel, S., McCarthy, M.D., \& Thorrold, S.R. (2015). Carbon and nitrogen isotope fractionation of amino acids in an avian marine predator, the gentoo penguin (Pygoscelis papua). Ecology and Evolution, 5: 1278-1290. 
McMahon, K.W., \& McCarthy, M.D. (2016). Embracing variability in amino acid $\delta^{15} \mathrm{~N}$ fractionation: mechanisms, implications, and applications for trophic ecology. Ecosphere, 7: e01511. 10.1002/ecs2.1511.

Meir, M., \& Ar, A. (1987). Improving turkey poult quality by correcting incubator humidity to match eggshell conductance. British Poultry Science, 28: 337-342.

Morrison, R.I.G., \& Hobson, K.A. (2004). Use of body stores in shorebirds after arrival on High-Arctic breeding grounds. The Auk, 121: 333-344.

Murphy, M.E. (1994). Amino-acid compositions of avian eggs and tissues - nutritional implications. Journal of Avian Biology, 25: 27-38.

Narushin, V.G. (2005). Egg geometry calculation using the measurements of length and breadth. Poultry Science, 84: 482-484.

NCP. (2012). Canadian Arctic Contaminants Assessment Report III: Mercury in Canada's North. Ottawa: Northern Contaminants Program (NCP), Aboriginal Affairs and Northern Development Canada, pp. 13-14.

Nielsen, J. M., Popp, B. N., \& Winder, M. (2015). Meta-analysis of amino acid stable nitrogen isotope ratios for estimating trophic position in marine organisms. Oecologia, 178: 631-642.

Norstrom, R.J., Hallett, D.J, Sonstegard, R.A. (1978). Coho salmon (Oncorhynchus kisutch) and herring gulls (Larus argentatus) as indicators of organochlorine contamination in Lake Ontario. Journal of the Fisheries Research Board of Canada, 35: 1401-1409.

NRCAN. (2014). Natural Resources Canada: Oil Supply and Demand. $<$ http://www.nrcan.gc.ca/energy/oil-sands/18086>.

Oswald, C.J., \& Carey, S.K. (2016). Total and methylmercury concentrations in sediment and water of a constructed wetland in the Athabasca Oil Sands Region. Environmental Pollution, 213: 628-637.

Pacyna, J.M., Travnikov, O., De Simone, F., Hedgecock, I.M., Sundseth, K., Pacyna, E.G., Steenhuisen, F., Pirrone, N., Munthe, J., Kindbom, K. (2016). Current and future levels of mercury atmospheric pollution on a global scale. Atmospheric Chemistry and Physics, 16: 12495-12511.

Peterson, B.J., \& R.W. Howarth. (1987). Sulfur, carbon and nitrogen isotopes used to trace organic matter flow in the salt-marsh estuaries of Sapelo Island, Georgia. Limnology and Oceanography, 32: 1195-1213. 
Popp, B.N., Graham, B.S., Olson, R.J., Hannides, C.C., Lott, M.J., Lopez-Ibarra, G.A., Galvan-Magana, F., \& Fry, B. (2007). Insight into the trophic ecology of yellowfin tuna, Thunnus albacares, from compound-specific nitrogen isotope analysis of proteinaceous amino acids. In Stable Isotopes as Indicators of Ecological Change; Dawson, T., Siegwolf, R., Eds.; Elsevier, Amsterdam, Holland, pp. 173-190.

Post, D. M. (2002). Using stable isotopes to estimate trophic position: models, methods, and assumptions. Ecology, 83: 703-718.

Rahn, H. (1984). Factors controlling the rate of incubation water loss in bird eggs. In Respiration and Metabolism of Embryonic Vertebrates; Seymour, R.S. Ed; Dr. W. Junk Publishers, Dordrecht, Netherlands, pp. 271-288.

Rahn, H., \& Paganelli C.V. (1989). The initial density of avian eggs derived from the tables of Schönwetter. Journal für Ornithologie, 130: 207-216.

Ramsar Convention Manual: a Guide to the Convention on Wetlands, $4^{\text {th }}$ ed.; Ramsar Convention Secretariat: Gland, Switzerland, 2006.

Romanoff, AL. (1930). Effect of composition of air on the growth and mortality of the chick embryo. Journal of Morphology, 50: 517-525.

Sackett, D.K., Drazen, J.C., Choy, C.A., Popp, B., \& Pitz, G.L. (2015). Mercury sources and trophic ecology for Hawaiian bottomfish. Environmental Science \& Technology, 49: 6909-6918.

Scheuhammer, A.M., Meyer, M.W., Sandheinrich, M.B., \& Murray, M.W. (2007). Effects of environmental methylmercury on the health of wild birds, mammals, and fish. Ambio, 36: 12-18.

Schroeder, W.H., \& Munthe, J. (1998). Atmospheric mercury - an overview. Atmospheric Environment, 32: 809-822.

Selin, N.E. (2009). Global biochemical cycling of mercury: a review. Annual Review of Environment and Resources, 34: 43-63.

Seminoff, J.A., Benson, S.R., Arthur, K.E., Eguchi, T., Dutton, P.H., Tapilatu, R.F., \& Popp, B.N. (2012). Stable isotope tracking of endangered sea turtles: Validation with satellite telemetry and $\delta^{15} \mathrm{~N}$ analysis of amino acids. PLOS ONE, 7: 10.1371/journal.pone.0037403.

Sharp, PJ. (1996). Strategies in avian breeding cycles. Animal Reproduction Science, 42: 505-513. 
Site C Environmental Impact Statement. (2013). Response to Working Group and Public Comments; Technical Memo, section 13 Methylmercury; BC Hydro, Vancouver, BC. <http://www.ceaa.gc.ca/050/documents_staticpost/63919/92870/Response_to _Working_Group_and_Public_Comments_Technical_Memos.pdf>.

StatSoft, Inc. STATISTICA (data analysis software system), version 12. Tulsa, OK, USA, 2013.

Stephens, P.A., Boyd, I.L., McNamara, J.M., \& Houston, A.I. (2009). Capital breeding and income breeding: their meaning, measurement, and worth. Ecology, 90: 2057- 2067.

St Louis, V.L., Rudd, J.W.M., Kelly, C.A., Beaty, K.G., Bloom, N.S., \& Flett, R.J. (1994). Importance of wetlands as sources of methylmercury to boreal forest ecosystems. Canadian Journal of Fisheries and Aquatic Science, 51: 10651076.

Stringham, G. (2012). Energy developments in Canada's oil sands. Developments in Environmental Science, 11: 19-34.

Su, G., Letcher, R.J., Moore, J.N., Williams, L.L., \& Grasman, K.A. (2017). Contaminants of emerging concern in Caspian tern compared to herring gull eggs from Michigan colonies in the Great Lakes of North America. Environmental Pollution, 1: 1-11.

Tamelander, T., Kivimae, C., Bellerby, R.G.J., Renaud, P.E., \& Kristiansen, S. (2009). Base-line variations in stable isotope values in an Arctic marine ecosystem: effects of carbon and nitrogen uptake by phytoplankton. Hydrobiologia, 630: 63-73.

Thomas, V. G. (1988). Body condition, ovarian hierarchies, and their relation to egg formation in Anseriform and Galliform species; In Acta XIX Congressus Internationalis Ornithologici; Quellet, H. Ed.; National Museum of Natural Science, Ottawa, Canada, pp. 353-363.

Timoney, K.P. (2013). Physical and hydrological processes of change. In The PeaceAthabasca Delta: portrait of a dynamic ecosystem; University of Alberta Press, Edmonton, Canada, pp. 167-189.

Ullrich, S.M., Tanton, T.W., \& Abdrashitova, S.A. (2001). Mercury in the aquatic environment: A review of factors affecting methylation. Critical Reviews in Environmental Science and Technology, 31: 241-293.

UNESCO/IUCN. (2017). Report of the Reactive Monitoring Mission to Wood Buffalo National Park, Canada. pp. 79. <http://whc.unesco.org/en/documents/156893>. 
Vleck, C.M., Vleck, D., \& Hoyt, D.F. (1980). Patterns of metabolism and growth in avian embryos. American Zoologist, 20: 405-416.

Wania, F., \& Mackay, D. (1996). Tracking the distribution of persistent organic pollutants. Environmental Science and Technology, 30: 390-396.

Weseloh, D.V.C., Moore, D.J., Hebert, C.E., de Solla, S.R., Braune, B.M., \& McGoldrick, D.J. (2011). Current concentrations and spatial and temporal trends in mercury in Great Lakes Herring Gull eggs, 1974-2009. Ecotoxicology, 20: 1644-1658.

Wiklund, J.A., Hall, R.I., Wolfe, B.B., Edwards, T.W.D., Farwell, A.J., \& Dixon, D.G. (2012). Has Alberta oil sands development increased far-field delivery of airborne contaminants to the Peace-Athabasca Delta? Science of the Total Environment, 433: 379-382.

Wolfe, F.W., Schwarzbach, S., Sulaiman, R.A. (1998). Effects of mercury on wildlife: a comprehensive review. Environmental Toxicology and Chemistry, 17: 146-160. 